\title{
Progress of a novel non-oxide Si-B-C-N ceramic and its matrix composites
}

\author{
Pengfei ZHANG, Dechang JIA*, Zhihua YANG, Xiaoming DUAN, Yu ZHOU \\ Institute for Advanced Ceramics, Harbin Institute of Technology, Harbin 150080, China
}

Received: October 9, 2012; Accepted: October 13, 2012

(C) The Author(s) 2012. This article is published with open access at Springerlink.com

\begin{abstract}
In the past twenty years, Si-B-C-N ceramic has attracted wide attention due to its special structure and outstanding properties. The ceramic generally has an amorphous or a nano-crystalline structure, and has excellent structural stability, oxidation resistance, creep resistance and high-temperature mechanical properties, etc. Thus, Si-B-C-N ceramic attracts many researchers and finds potential applications in transportation, aerocraft, energy, information, microelectronics and environment, etc. Much work has been carried out on its raw materials, preparation processes, structural evolution, phase equilibrium and high-temperature properties. In recent years, many researchers focus on its new preparation methods, the preparation of dense ceramic sample with large dimensions, ceramic matrix composites reinforced by carbon fiber or $\mathrm{SiC}$ whisker, or components with various applications. Research on Si-B-C-N ceramic will develop our insight into the relationship between structures and properties of ceramics, and will be helpful to the development of novel high-performance ceramics. This paper reviews the preparation processes, general microstructures, mechanical, chemical, electrical and optical properties, and potential applications of Si-B-C-N ceramic, as well as its matrix composites.
\end{abstract}

Key words: Si-B-C-N; ceramic; preparation method; microstructure; property

\section{Introduction to $\mathrm{Si}-\mathrm{B}-\mathrm{C}-\mathrm{N}$ ceramic}

Si-B-C-N ceramic is originally prepared by the organic polymer pyrolyzing route [1,2]. Generally, a kind of special organic polymer precursor, such as solid poly (boro)silazanes or polysilylcarbodiimides, is pyrolyzed at $1000{ }^{\circ} \mathrm{C}-1400{ }^{\circ} \mathrm{C}$ in an inert atmosphere for several hours [3-5]. During the pyrolyzing process, side-chain

\footnotetext{
* Corresponding author.

E-mail: dcjia@hit.edu.cn
}

groups break; organic molecules with low molecular weight volatilize; crosslinking and curing take place in the polymer precursor. When pyrolyzing is finished, the remaining substance is an inorganic ceramic, mainly consisting of $\mathrm{Si}, \mathrm{B}, \mathrm{C}$ and $\mathrm{N}$. The as-pyrolyzed ceramic generally has an amorphous structure [6], a high structural stability $[7,8]$, a large viscosity and a nice oxidation resistance $[9,10]$. When the amorphous ceramic is annealed at $1800{ }^{\circ} \mathrm{C}-2000{ }^{\circ} \mathrm{C}$ in an inert atmosphere for several hours, its structure will change into a thermodynamically stable one $[8,11]$. That is, the amorphous ceramic will crystallize into a nano composite ceramic, with a phase composition of 
B-N-C, $\mathrm{SiC}$ and/or $\mathrm{Si}_{3} \mathrm{~N}_{4}$. The as-annealed nano ceramic has high structure stability and nice creep resistance [12,13]. The research of Seyferth et al in 1990 shows that the reaction of $\mathrm{H}_{3} \mathrm{~B} \cdot \mathrm{S}\left(\mathrm{CH}_{3}\right)_{2}$ with $\left(\mathrm{CH}_{3} \mathrm{SiHNH}\right)_{n}$ cyclic oligomers prepared by the ammonolysis of methyldichlorosilane $\left(\mathrm{CH}_{3} \mathrm{SiHCl}_{2}\right)$ results in the volatilization of hydrogen and the formation of cross-linked products that contain borazine rings as well as boron atoms, which are linked to three nitrogen atoms [14]. Pyrolysis of the products in an argon stream gives a high yield of black "borosilicon carbonitride". In 1992, Baldus et al employed the aminolysis and polycondensation reactions between tri(chlorosilylamino)borane and methylamine to synthesize poly(boro)silazanes [1]. Pyrolysis of this polymer precursor in an inert atmosphere produces a $\mathrm{SiBN}_{3} \mathrm{C}$ ceramic, whose structure is still amorphous even at $1900{ }^{\circ} \mathrm{C}$ in the nitrogen atmosphere. In 1996, Riedel et al prepared a kind of white poly(boro)silazanes powder, using hydroboration, aminolysis and polycondensation reactions between methylvinylchlorosilane and borane [15]. Pyrolysis of this precursor at $1000{ }^{\circ} \mathrm{C}$ in the argon atmosphere produces a kind of $\mathrm{Si}-\mathrm{B}-\mathrm{C}-\mathrm{N}$ ceramic, whose structure is amorphous at temperatures lower than $1700{ }^{\circ} \mathrm{C}$ in air and does not lose weight even at $2000{ }^{\circ} \mathrm{C}$ in an inert atmosphere. At present, using the polymer pyrolyzing route, various kinds of Si-B-C-N ceramics can be prepared, such as bulk ceramic, ceramic fiber, ceramic coating, porous ceramic, ceramic matrix composite or ceramic microdevice [16-19]. These products have found potential applications in aerospace craft, traffic transport system, and micromachine or microcircuit used at elevated temperatures, etc [20].

Besides the organic polymer pyrolyzing route, two other methods are also developed in recent years for the preparation of Si-B-C-N ceramic. In 2005, Vlcek et al prepared an amorphous Si-B-C-N film on silicon substrate by a reactive magnetron sputtering technique [21]. The as-deposited film has a smooth surface, high hardness, high structural stability, nice oxidation resistance, controllable electrical resistance and even photoluminescence property [22-24]. In 2007, Yang et al developed the mechanical alloying plus sintering method to prepare Si-B-C-N bulk ceramic [25]. They fabricated amorphous Si-B-C-N powder by a high-energy ball mill, using silicon powder, graphite powder and h-BN powder as raw materials. Hot pressing the as-milled amorphous powder at $1900^{\circ} \mathrm{C}$ in the nitrogen atmosphere for $30 \mathrm{~min}$ produced a nano composite ceramic, with a phase composition of B-N-C and $\mathrm{SiC}[26,27]$.

Because of its special structure and outstanding properties, Si-B-C-N ceramic is widely concerned and studied in the past twenty years or so. Researchers have carried out much work on its raw materials, preparation processes, structural features and high-temperature properties. The number of publications on the topic of "Si-B-C-N ceramic" increases quickly since 1990, as revealed by the statistic data shown in Fig. 1. Currently, important researchers and institutes in the study of Si-B-C-N ceramic, prepared by the organic polymer pyrolyzing route, include Aldinger $\mathrm{F}$, Weinmann $\mathrm{M}$, Bill $\mathrm{J}$, and Seifert H J, et al [28-30], in Universitat Stuttgart and Max-Planck-Institut fur Metallforschung, Germany; Riedel $\mathrm{R}$ et al [31], in Technische Universitat Darmstadt, Germany; Jansen $\mathrm{M}$ et al [32], in Universitat Bonn, Germany; Sneddon L G et al [33], in University of Pennsylvania, USA; Kim D P et al [34], in Chungnam National University, South Korea; and Nesper R et al [35], in ETH Zurich, Switzerland. Researchers, employing the reactive magnetron sputtering technique to prepare Si-B-C-N film, mainly include Vlcek $\mathrm{J}$ et al [36], in University of West Bohemia, Czech Republic and Vijayakumar A et al [24], in University of Central Florida, USA. In recent years, Jia D C et al [37,38], in Harbin Institute of Technology, China, developed the mechanical alloying plus sintering method to prepare Si-B-C-N bulk ceramic. Here, we summarize the current research

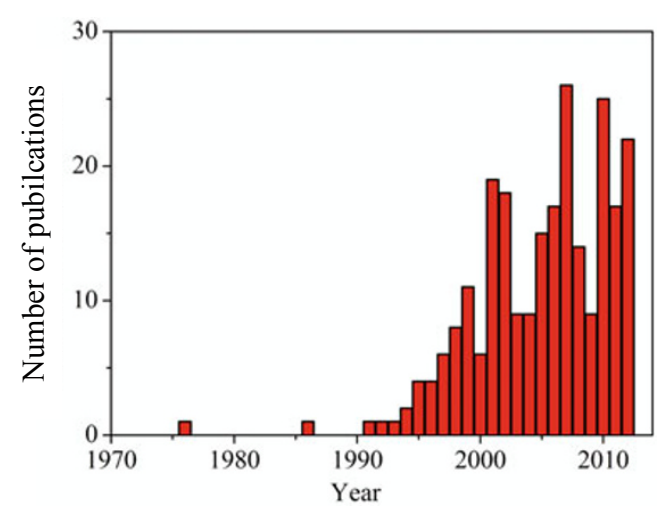

Fig. 1 The number of publications on the topic of "Si-B-C-N ceramic" from 1976 up to 2012. The data come from the statistic of the searching results by http://scholar.google.com/. 
status of Si-B-C-N ceramic, including its main preparation processes, general microstructures, properties and potential applications, as well as those of its matrix composites.

\section{Preparation methods of Si-B-C-N ceramic}

So far, organic polymer pyrolyzing route [39], chemical vapor deposit (CVD) [40], reactive magnetron sputtering and mechanical alloying plus sintering technique have been reported to be adopted to prepare different types of Si-B-C-N ceramics $[41,42]$. The organic polymer pyrolyzing route had been developed and used for more than twenty years. Most of the research results on Si-B-C-N ceramics are obtained by this method and most researchers are still focusing on this method. When the CVD technique is adopted, an organic polymer is deposited on a substrate, and the deposited polymer is then pyrolyzed at high temperatures to produce an inorganic ceramic coating. It has a similar principle like that in the preparation Si-B-C-N bulk ceramic by the organic polymer pyrolyzing route. The reactive magnetron sputtering and mechanical alloying plus sintering techniques are developed in recent years, the results are relatively rare and the studies are still in their infancy.

\subsection{Organic polymer pyrolyzing route}

For the preparation of Si-B-C-N ceramic by the organic polymer pyrolyzing route, a kind of special organic polymer, such as poly(boro)silazanes or polysilylcarbodiimides, is required to be synthesized first [43]. When the polymer precursor is heated, side-chain groups will break; organic molecules with low molecular weight will volatilize; dehydrogenation, cross-linking, and polycondensation will occur in the polymer [35]. When temperature is increased to $1000{ }^{\circ} \mathrm{C}$, pyrolyzing finishes and the remaining product is an inorganic ceramic with an amorphous structure [44]. For the preparation of Si-B-C-N ceramic by this method, five steps are generally required: organic polymer synthesis; distillation, cross linking and curing of the polymer; grinding and shaping of the polymer precursor; pyrolyzing of the shaped precursor at high temperatures in an inert atmosphere; and annealing the as-pyrolyzed ceramic at higher temperatures in an inert atmosphere [3,12,39,45-47]. Figure 2 gives a schematic of the preparation process.

(1) Organic polymer synthesis: Monomer organics or oligomers are normally used as raw materials; they are dissolved in organic solvents and then polymerized via hydroboration, amination or dehydrocyclization reactions. Solvents are then volatilized and high polymers are obtained. Take monomer route as an example, the polymer synthetic process generally includes the following steps: First, dissolving methylchlorosilane in toluene, pouring dimethylsulfideborane into the continuously stirred solution slowly at a constant temperature. In this way,

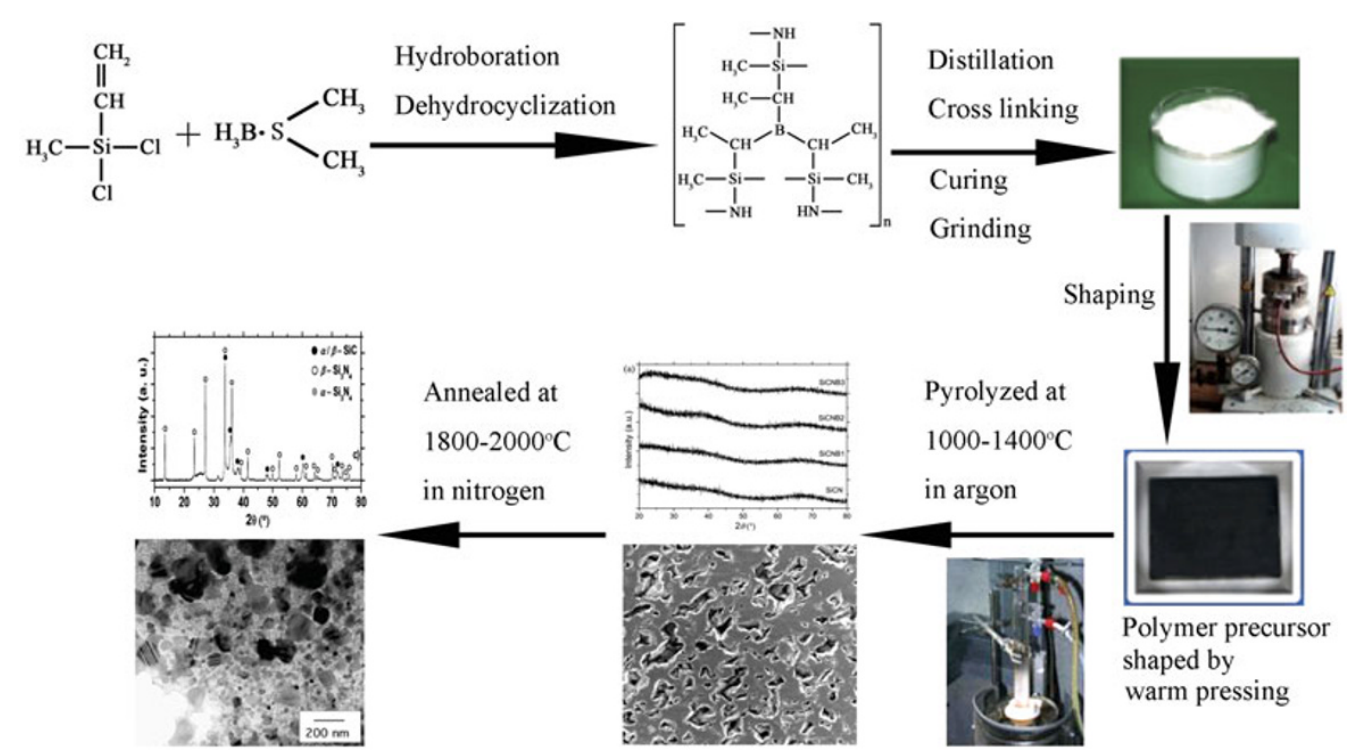

Fig. 2 A schematic showing the preparation process of Si-B-C-N ceramic by the organic polymer pyrolyzing route $[12,13,20,29,39,48,49]$. 
hydroboration may occur between the above two organic compounds. Second, stirring the above mixture at room temperature for several hours to volatilize the solvent, and then heating the reaction products in vacuum to remove water and obtain a colorless oily liquid. Third, dissolving the obtained oily liquid in tetrahydrofuran, and continuously stirring the solution in an ammonia stream for several hours. The last, filtering the above mixture and heating the reaction products in vacuum to obtain a solid poly(boro)silazane.

(2) Distillation, cross linking and curing of the synthesized polymer: Heating the obtained solid polymer distiller to $300{ }^{\circ} \mathrm{C}-400{ }^{\circ} \mathrm{C}$ in vacuum and annealing it at this temperature range for several hours. In this way, organic molecules with low molecular weight are removed, and cross linking and curing will occur in the polymer. In the following heating process, the distilled polymer will not melt.

(3) Grinding and shaping of the obtained polymer precursor: The distilled polymer is powdered, and then pressed into a special shape at $200{ }^{\circ} \mathrm{C}-400{ }^{\circ} \mathrm{C}$ in the argon atmosphere.

(4) Pyrolyzing the shaped polymer precursor at high temperatures in an inert atmosphere: Heating the shaped polymer precursor to $1000{ }^{\circ} \mathrm{C}-1400{ }^{\circ} \mathrm{C}$ in the argon atmosphere and pyrolyzing it at this temperature range for $2 \mathrm{~h}-5 \mathrm{~h}$. An amorphous ceramic containing $\mathrm{Si}$, $\mathrm{B}, \mathrm{C}$, and $\mathrm{N}$ are prepared.

(5) Annealing the as-pyrolyzed ceramic at higher temperatures in an inert atmosphere: Heating the as-pyrolyzed amorphous ceramic to $1800{ }^{\circ} \mathrm{C}-2000{ }^{\circ} \mathrm{C}$ and annealing it at this temperature range for $3 \mathrm{~h}-5 \mathrm{~h}$, then the amorphous ceramic will crystallize into a nano composite ceramic.

Due to the difference in raw materials, polymer types, polymer synthetic processes, or polymer pyrolyzing processes, the chemical compositions, microstructures, and properties of the prepared ceramics may be very different. In other words, the structure and the property of the polymer-derived Si-B-C-N ceramic can be tailored by controlling the raw materials or various operation parameters [5]. By this method, various atoms or tetrahedrons are uniformly distributed in the ceramic; the ceramic composition can be adjusted conveniently; the product contains no impurity phase at the grain boundary; and the pyrolyzing process is carried out at relatively low temperatures. However, shortcomings also exist in this method. For example, raw materials and organic solvents, which are usually very expensive and poisonous, may result in high cost of products, damage to operators and severe pollution to environment. During the polymer pyrolyzing process, a large amount of gas volatilizes, and large mass loss and volume shrinkage occur in the ceramic sample. These may lead to the formation of a large number of pores or even cracks in products [13]. Additionally, the preparation process is complex and the ceramic structure and ceramic property are greatly affected by complicated factors. Generally, the organic polymer pyrolyzing route is applicable to the preparation of ceramic fiber [50], ceramic coating [51], porous ceramic [18], or fiber reinforced ceramic matrix composite [19]. However, by this method, it is difficult to prepare a dense bulk ceramic particularly with large dimensions [12]. Although a pressure assisted pyrolyzing method is developed in recent years and the bulk density of the ceramic is significantly increased [52], the ceramic sample diameter is still around $1 \mathrm{~cm}$ or so [12].

\subsection{Reactive magnetron sputtering}

The reactive magnetron sputtering method is normally used to prepare various films on substrates. In recent years, it is also developed to prepare the Si-B-C-N film on ceramic or metallic substrates $[21,53,54]$. By this method, a mixture of silicon, graphite and boron are usually used as target, and silicon, silicon oxide or other alloys as substrates. The preparation process mainly includes the following steps. First, the reaction chamber is evacuated and then filled with a mixed gas of nitrogen and argon. Second, the mixed gas is ionized by a glow discharge, and the materials on the target surface are changed into ions or gaseous atoms, because of the bombardment of electrons or nitrogen/argon ions. Finally, atoms from the target and nitrogen ions are deposited on the substrate, forming a ceramic film, containing $\mathrm{Si}, \mathrm{B}, \mathrm{C}$, and $\mathrm{N}$. The film is usually smooth and amorphous, with a uniform thickness of $1-5 \mu \mathrm{m}$ [41]. The diagram in Fig. 3 shows the basic principle of preparing Si-B-C-N film by the ion-beam assisted magnetron sputtering method. The generally used substrates include silicon, silicon oxide, silicon carbide and copper. Silicon plus boron carbide or Si-C-B is usually selected as target [21]. The bias voltage and the temperature of the target are normally set as $-100 \mathrm{~V}$ and $190{ }^{\circ} \mathrm{C}-450{ }^{\circ} \mathrm{C}$, respectively [23]. The composition, structure and property of the 


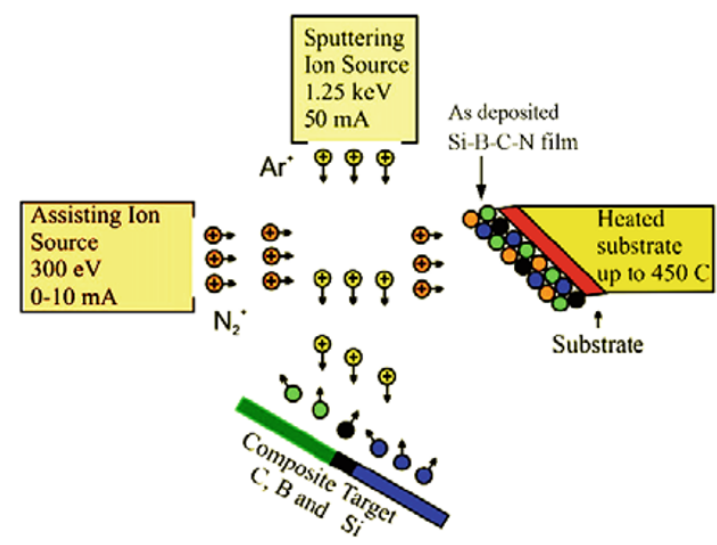

Fig. 3 A schematic showing the principle of preparing Si-B-C-N film by the ion-beam assisted magnetron sputtering system [41].

deposited film can be altered by controlling the composition of the mixed gas or target, the bias voltage or the temperature of the substrate. This method brings little pollution to operator or environment, and can produce ceramic films at relatively low temperatures. It is applicable to the preparation of amorphous Si-B-C-N film on various substrates, but is incompetent to fabricate bulk ceramic or ceramic fiber.

\subsection{Mechanical alloying plus sintering method}

By this method, silicon powder, graphite powder and h-BN powder are currently used as raw materials, and the preparation process generally consists of two steps, as revealed by the diagram shown in Fig. 4 $[26,27,37,55]$. First, raw powders, together with silicon nitride or zirconia balls, are put into in silicon nitride or zirconia jars, and then the jars are sealed under the protection of argon atmosphere. Two jars are fixed on a planetary or vibrating ball mill. After setting milling parameters, the powder mixtures are high-energy ball milled to produce an amorphous Si-B-C-N powder. Second, the amorphous powder is sintered by hot pressing or SPS technique in the nitrogen atmosphere to produce a dense bulk ceramic. For this method, various inexpensive inorganic powders can be used as raw materials, such as powders of silicon, boron, carbon, boron nitride, silicon carbide, silicon nitride, boron carbide, etc; the preparation process is simple and causes little pollution; and more importantly, dense bulk ceramics especially with large dimensions can be easily fabricated. However, using this technology, the distribution of various atoms is not as uniform as that by the organic polymer pyrolyzing route. Densification of the as-milled powder employs a relatively high temperature, which may result in the crystallization of the amorphous powder and is unfavorable for the preparation of dense bulk ceramics with completely amorphous structures. Therefore, the mechanical alloying plus sintering method is applicable to the preparation of dense or porous Si-B-C-N bulk ceramics with simple shapes, but it is inadequate to fabricate ceramic coating, ceramic fiber or ceramic film.

\section{Microstructure of Si-B-C-N ceramic}

Most of the Si-B-C-N ceramics have a common structural character, that is, no matter the as-pyrolyzed
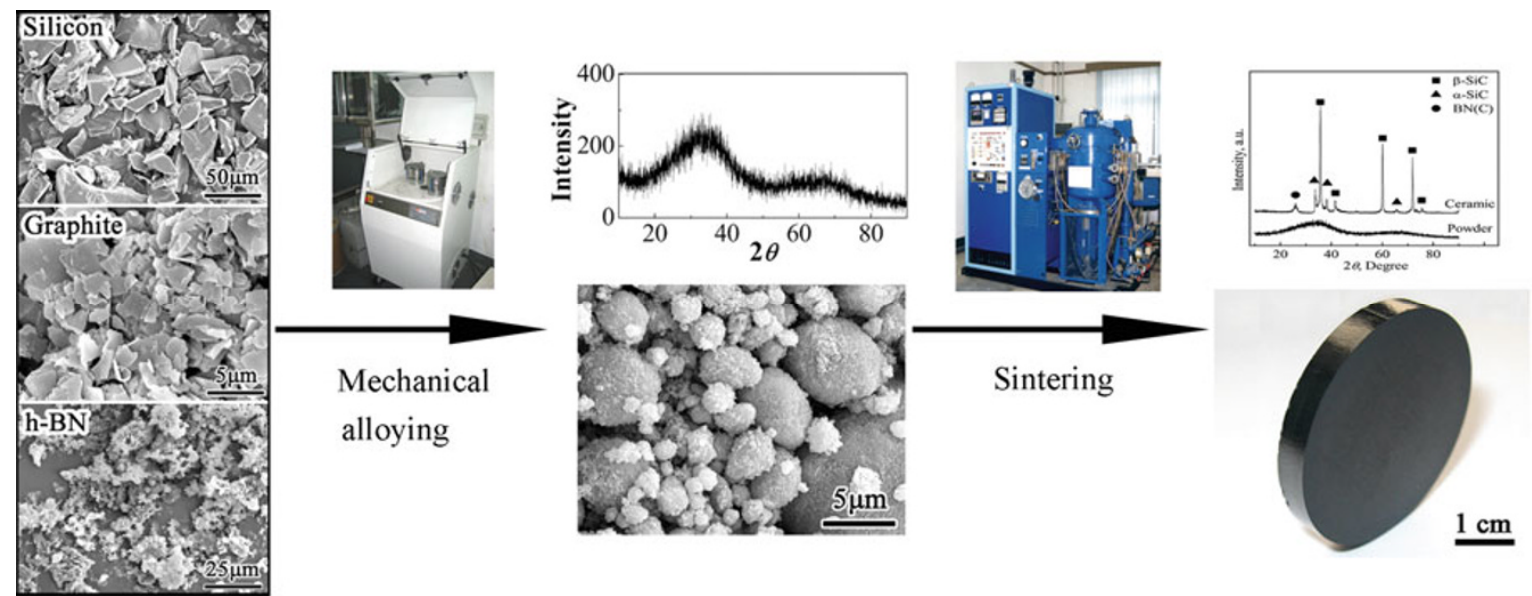

Fig. 4 A schematic showing the preparation process of amorphous Si-B-C-N powder and dense bulk ceramic by the mechanical alloying plus sintering method $[26,37,55]$. 
bulk ceramic or ceramic fiber prepared by the organic polymer pyrolyzing route, the as-deposited ceramic film prepared by reactive magnetron sputtering, or the as-milled ceramic powder fabricated by mechanical alloying, they all have amorphous structures $[17,41,42]$. When they are annealed or sintered at temperatures higher than their preparation temperatures, these amorphous ceramics will crystallize into nano composite ones with the phase compositions of B-N-C, $\mathrm{SiC}$ and/or $\mathrm{Si}_{3} \mathrm{~N}_{4}$ [11,37,56]. Generally, the composition homogeneity, structural stability, crystallization process, phase composition and properties of the prepared ceramics are greatly affected by the variation of preparation method, technological process, raw materials or chemical compositions.

\subsection{Microstructure of the polymer-derived amorphous Si-B-C-N ceramic}

When heating an organic polymer, such as poly(boro)silazane, to $400{ }^{\circ} \mathrm{C}-600{ }^{\circ} \mathrm{C}$, side-chain groups $\left(\mathrm{Si}-\mathrm{CH}_{3}, \mathrm{NH}-\mathrm{Si}, \mathrm{C}-\mathrm{CH}_{3}\right)$ will break, and organic molecules with low molecular weight will volatilize. When the polymer is heated to $1000{ }^{\circ} \mathrm{C}$ $1400{ }^{\circ} \mathrm{C}$, most of hydrogen will volatilize, producing an inorganic ceramic with uniformly distributed $\mathrm{Si}, \mathrm{B}$, $\mathrm{C}$, and $\mathrm{N}$ atoms. Research shows that the as-pyrolyzed ceramic has an amorphous structure, with no identifiable diffraction peaks in its XRD spectrum, as shown in Fig. 5a. The HRTEM image displayed in Fig. $5 \mathrm{~b}$ reveals that atoms in the amorphous ceramic are thoroughly disordered. The formation of the amorphous structure may be greatly attributed to the uniform distribution of different types of atoms, and to the formation of strong covalent bonds between them.

However, not all the as-pyrolyzed Si-B-C-N ceramics have completely amorphous structures. When raw materials or technical parameters are changed, the as-pyrolyzed ceramic may contain nano crystallites in its amorphous matrix. As indicated in Fig. 6a, the XRD spectrum of this kind of Si-B-C-N ceramic has a weak diffraction peak at about $36^{\circ}$ or so, which corresponds to the diffraction of $\mathrm{SiC}$. The peak has a weak intensity and a broad full width at half maximum, suggesting that the crystallites may have a low crystallinity or very small grain size. However, the presence of this diffraction peak suggests that $\mathrm{SiC}$ crystallites have formed in the amorphous matrix. The HRTEM image shown in Fig. 6b displays the atomic arrangement in the ceramic. Most areas of the ceramic are composed
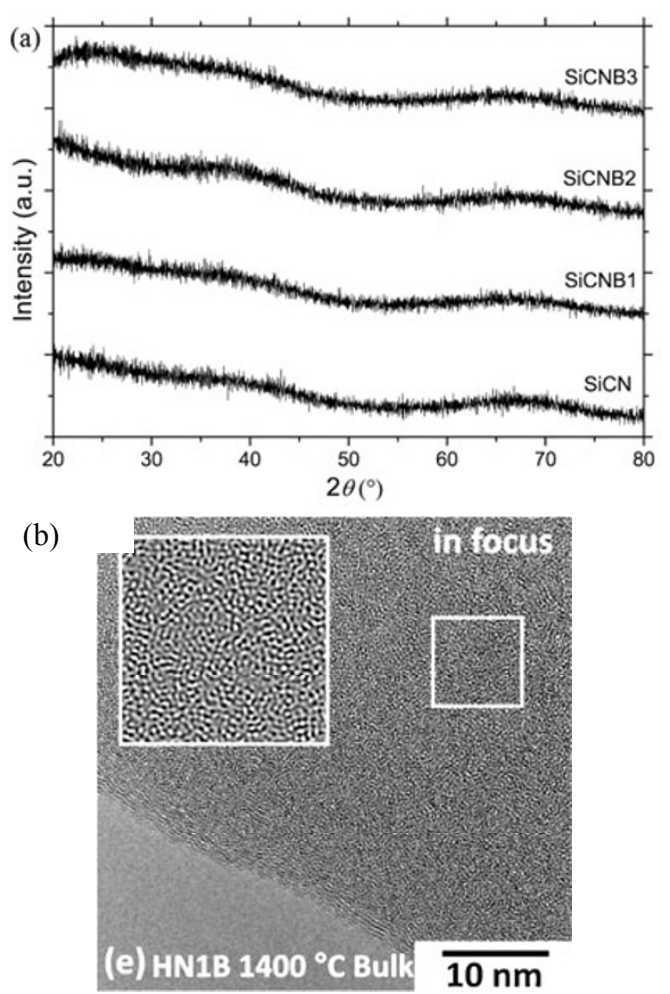

Fig. 5 General XRD spectra (a) [49] and HRTEM image (b) [6] of the as-pyrolyzed Si-B-C-N ceramic.

(a)

as- pyrolysed
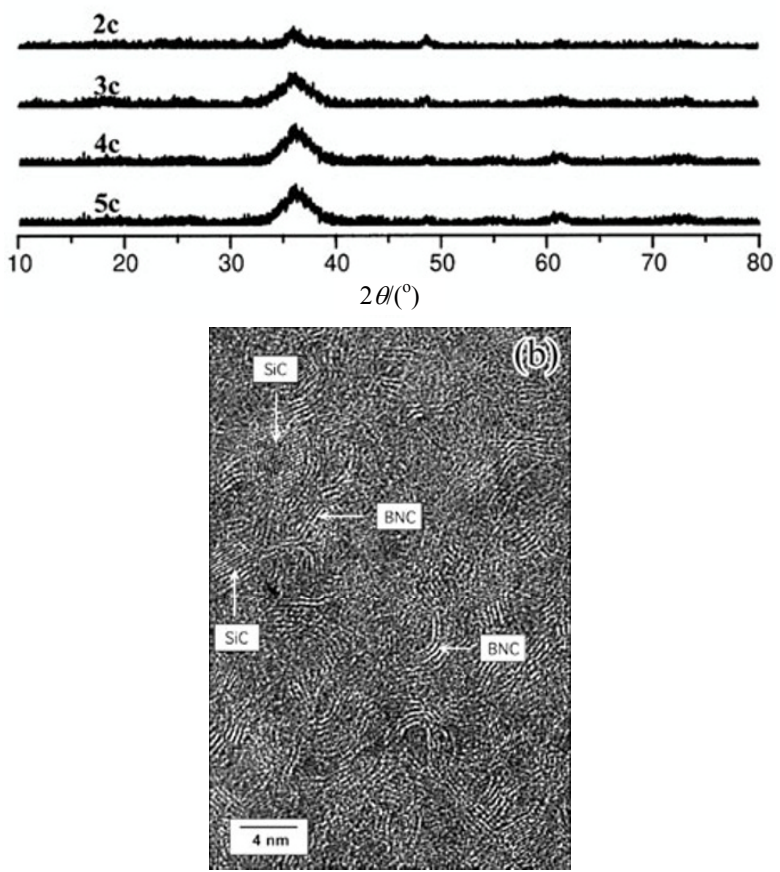

Fig. 6 The XRD spectra (a) and HRTEM micrograph (b) of the as-pyrolyzed Si-B-C-N ceramic, showing the crystallization $\mathrm{SiC}$ and $\mathrm{B}-\mathrm{N}-\mathrm{C}[7,57]$. 
of disordered atoms, while some zones show the primary conformation of crystallite. The crystallites have very small sizes and mainly consist of $\mathrm{SiC}$ and B-N-C, which are different in their interplanar distances and grain shapes. While $\mathrm{SiC}$ crystallite has a cubic structure like that in sphalerite, B-N-C more likely possesses a turbostratic structure, similar to that in turbostratic boron nitride. When employing different raw materials, chemical composition, or synthetic processes, the crystallinity of the as-pyrolyzed ceramic may be varied.

The chemical bonding state between different atoms in the amorphous $\mathrm{Si}-\mathrm{B}-\mathrm{C}-\mathrm{N}$ ceramic is always not clear, and two conformations are proposed by researchers, as revealed in Fig. 7. In the diagram shown in Fig. 7a, it is thought that the side-chain breaking, gas volatilization, polymer cross linking and polycondensation may produce an inorganic ceramic with a rather uniform distribution of $\mathrm{Si}, \mathrm{B}, \mathrm{C}$ and $\mathrm{N}$ atoms. Because of the formation of strong covalent bonds between different atoms, the atomic diffusion and the crystallization may be very difficult. These are
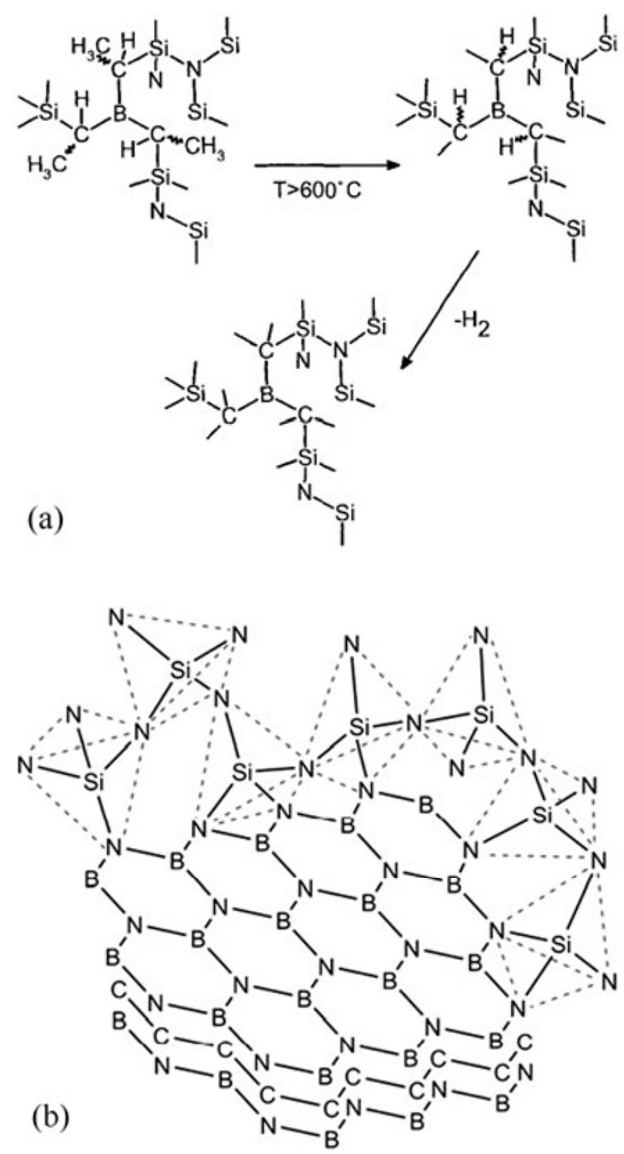

Fig. 7 Two structural schematics of the polymerderived amorphous Si-B-C-N ceramics $[29,46]$. considered important factors contributing to the formation of amorphous structure and to the high structural stability of the as-pyrolyzed ceramic. This model is most likely an inference from the molecular structure and the pyrolyzing process of organic polymers. However, many research results provide evidences for the other model [32], as shown in Fig. 7b. By this model, it is considered that the as-pyrolyzed Si-B-C-N ceramic consists of two kinds of amorphous phases: amorphous $\operatorname{SiC}_{x} \mathrm{~N}_{4-x} \quad(0 \leqslant x \leqslant 4)$ and turbostratic B-N-C. They have rather small sizes and very uniform distribution in the ceramic. At the boundary between the two phases, chemical bonds, such as, Si-C-B, Si-C-N, and Si-N-B, may exist. It is generally considered that $\mathrm{B}-\mathrm{N}-\mathrm{C}$ is not only hard to crystallize, but also can block atomic diffusion and suppress grain growth of $\mathrm{SiC}$. As a result, it greatly contributes to the formation of amorphous structure and the structural stability of the as-pyrolyzed ceramic.

\subsection{Structural stability of the polymer-derived amorphous Si-B-C-N ceramic}

It is found that the polymer-derived amorphous Si-B-C-N ceramic has a rather high structural stability. The ceramic has little weight loss even at $2000{ }^{\circ} \mathrm{C}$ in an inert atmosphere, as suggested in Fig. 8a. The weight stability is better than that of $\mathrm{Si}_{3} \mathrm{~N}_{4}$ or Si-C-N ceramic, which shows severe weight loss at temperatures higher than $1500{ }^{\circ} \mathrm{C}$ in the same atmosphere. The higher structural stability of the Si-B-C-N ceramic may be related to its special structure described in Fig. 7b. The uniformly distributed B-N-C retards atomic diffusion and lowers the activity of carbon atoms. Additionally, it wraps $\mathrm{SiC}_{x} \mathrm{~N}_{4-x}$, resulting in the blocking of gas release, the increasing of local nitrogen pressure, and the suppression of decomposition or crystallization. It is also found that when the amorphous ceramic is heated in an inert atmosphere, it does not crystallize even at $1700{ }^{\circ} \mathrm{C}$, as revealed in Fig. 8b. Because of the formation of strong covalent bonds, the small size and the uniform distribution of each phase, the atomic diffusion may be very difficult, thus crystallization is prohibited. When the as-pyrolyzed amorphous ceramic is heated to a temperature between $1800{ }^{\circ} \mathrm{C}-2000{ }^{\circ} \mathrm{C}$, it will crystallize into nano composite ceramic, consisting of B-N-C, $\mathrm{SiC}$ and $\mathrm{Si}_{3} \mathrm{~N}_{4}$. When the temperature is higher than $2000{ }^{\circ} \mathrm{C}, \mathrm{Si}_{3} \mathrm{~N}_{4}$ will decompose and the nano ceramic is composed of 


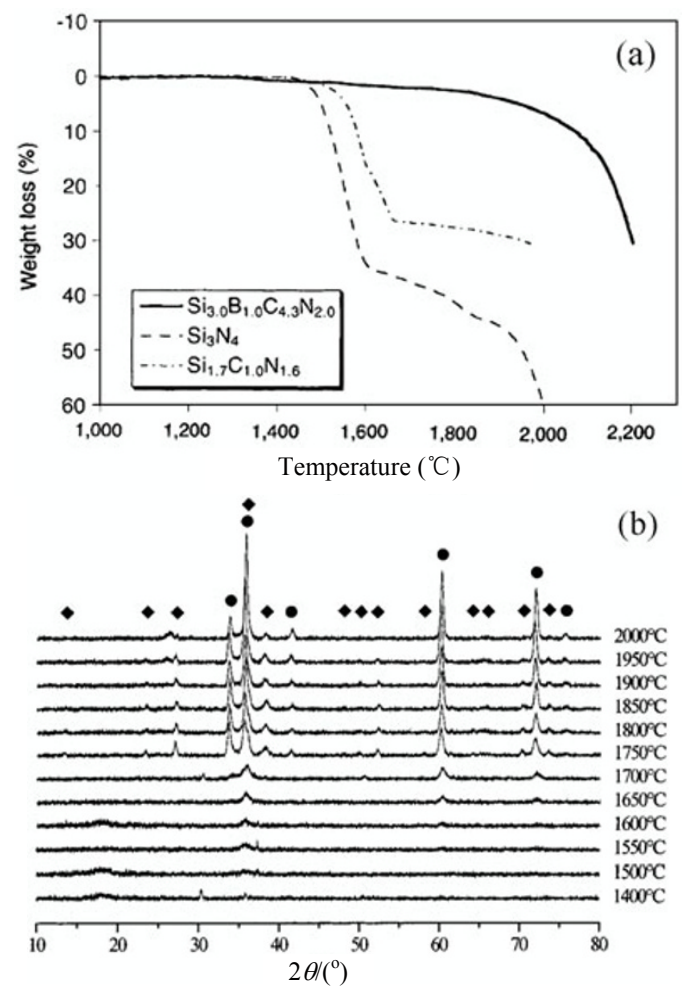

Fig. 8 The thermogravimetric curve of the polymer-derived amorphous $\mathrm{Si}-\mathrm{B}-\mathrm{C}-\mathrm{N}$ ceramic in the helium atmosphere (a) [15], and the XRD patterns of the Si-B-C-N ceramics annealed at different temperatures for $3 \mathrm{~h}$ in the nitrogen atmosphere $\left(\bullet, \alpha-\mathrm{SiC} ; \bullet, \beta-\mathrm{Si}_{3} \mathrm{~N}_{4}\right)($ b) [8].

B-N-C and SiC. When raw materials or polymer synthetic process changes, the crystallization or decomposition temperature of the as-pyrolyzed ceramic may be varied.

Results from thermodynamic calculation show that the polymer-derived amorphous $\mathrm{Si}-\mathrm{B}-\mathrm{C}-\mathrm{N}$ ceramic actually has a metastable structure. The images shown in Fig. 9 are three isothermal sections of the calculated
Si-B-C-N phase diagram, with a boron content of 15 at.\% and a nitrogen pressure of 1 bar. For example, when the chemical composition of the ceramic is located in the phase region of $\mathrm{Si}_{3} \mathrm{~N}_{4}+\mathrm{SiC}+\mathrm{C}+\mathrm{BN}$ at $1400{ }^{\circ} \mathrm{C}$, the stable ceramic should consist of these four kinds of crystals, as suggested in Fig. 9a. When the temperature is increased to $1600{ }^{\circ} \mathrm{C}, \mathrm{Si}_{3} \mathrm{~N}_{4}$ will react with free carbon to form $\mathrm{Si}$ and $\mathrm{N}_{2}$, and the stable ceramic will be composed of $\mathrm{Gas}+\mathrm{SiC}+\mathrm{C}+\mathrm{BN}$, as indicated in Fig. 9b. Of course, if higher content of nitrogen or silicon is contained, the stable ceramic may consist of $\mathrm{Gas}+\mathrm{Si}_{3} \mathrm{~N}_{4}+\mathrm{SiC}+\mathrm{BN}$ or Liquid $+\mathrm{Si}_{3} \mathrm{~N}_{4}+$ $\mathrm{SiC}+\mathrm{BN}$ at $1600{ }^{\circ} \mathrm{C}$. At $2000{ }^{\circ} \mathrm{C}$, the residual $\mathrm{Si}_{3} \mathrm{~N}_{4}$ may decompose, and the stable ceramic will be made up of $\mathrm{Gas}+\mathrm{SiC}+\mathrm{C}+\mathrm{BN}$ or $\mathrm{Gas}+\mathrm{Liquid}+\mathrm{SiC}+\mathrm{BN}$. The above discussion reveals that the stable $\mathrm{Si}-\mathrm{B}-\mathrm{C}-\mathrm{N}$ ceramic at a standard atmosphere is actually a composite ceramic, consisting of crystals of simple substances or compounds. The amorphous structure is metastable, and its formation may be due to the changed thermodynamic or kinetic conditions in ceramic. When the amorphous ceramic is used at high temperatures for a long duration, it may crystallize, decompose or lose weight, and macro deformation may occur to the ceramic components.

\subsection{Structure and its stability of the as-annealed nano $\mathrm{Si}-\mathrm{B}-\mathrm{C}-\mathrm{N}$ ceramic}

Annealed at $1800{ }^{\circ} \mathrm{C}-2000{ }^{\circ} \mathrm{C}$ for several hours, the as-pyrolyzed amorphous Si-B-C-N ceramics may crystallize and most of them may change into nano composite ceramics with phase compositions of $\mathrm{SiC}$, $\mathrm{Si}_{3} \mathrm{~N}_{4}$ and B-N-C. The results in Fig. 10 reveal the typical XRD spectra and HRTEM image of the as-annealed nano Si-B-C-N composite ceramic. The

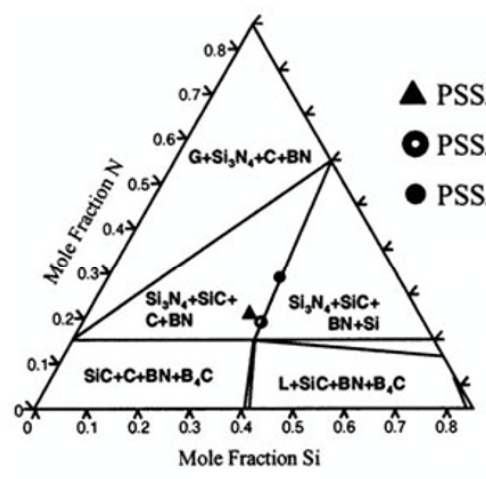

(a) $1673 \mathrm{~K}$

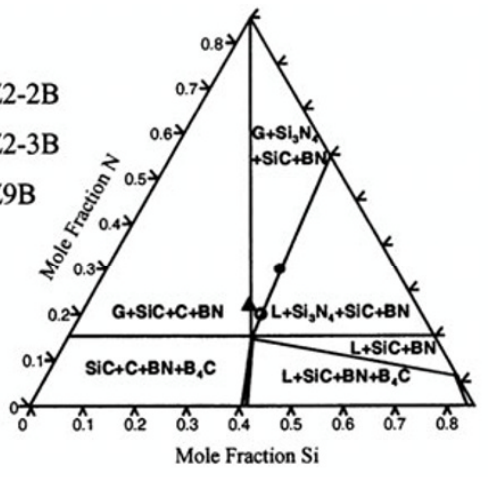

(b) $1873 \mathrm{~K}$

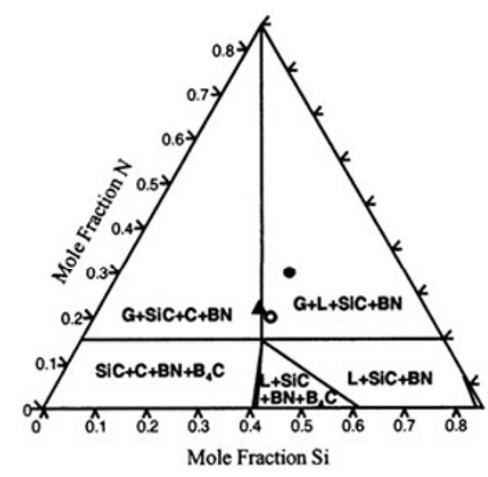

(c) $2273 \mathrm{~K}$

Fig. 9 Isothermal sections of the calculated Si-B-C-N phase diagram with 15 at.\% boron and 1 bar $\mathrm{N}_{2}$ at three different temperatures [58]. 
grain sizes of $\mathrm{SiC}$ and $\mathrm{Si}_{3} \mathrm{~N}_{4}$ are around $100 \mathrm{~nm}$, and most of the grains contain a large amount of stacking faults, twins, or disordered atoms, etc, as shown in Figs. $10 \mathrm{~b}$ and 11a. Additionally, areas with disordered atoms also exist next to the crystal grains. The appearance of $\mathrm{Si}_{3} \mathrm{~N}_{4}$ at such high temperatures may be attributed to the special structures of the ceramic. B-N-C wraps $\mathrm{Si}_{3} \mathrm{~N}_{4}$ grains, retards the reaction between $\mathrm{Si}_{3} \mathrm{~N}_{4}$ and carbon, increases the nitrogen pressure, and hence depresses the decomposition of $\mathrm{Si}_{3} \mathrm{~N}_{4}$. Being different from $\mathrm{SiC}$ and $\mathrm{Si}_{3} \mathrm{~N}_{4}, \mathrm{~B}-\mathrm{N}-\mathrm{C}$ has no fixed shape and a much lower crystallinity. The results in HRTEM image suggests that B-N-C has a turbostratic structure, similar to that in turbostratic boron nitride, as shown in Fig. $11 \mathrm{~b}$. It is generally considered that B-N-C is composed of alternately arranged atomic layers of turbostratic carbon and turbostratic boron nitride. This phase is not only hard to crystallize, but greatly affects the structural stability and the crystallization process of Si-B-C-N ceramic.
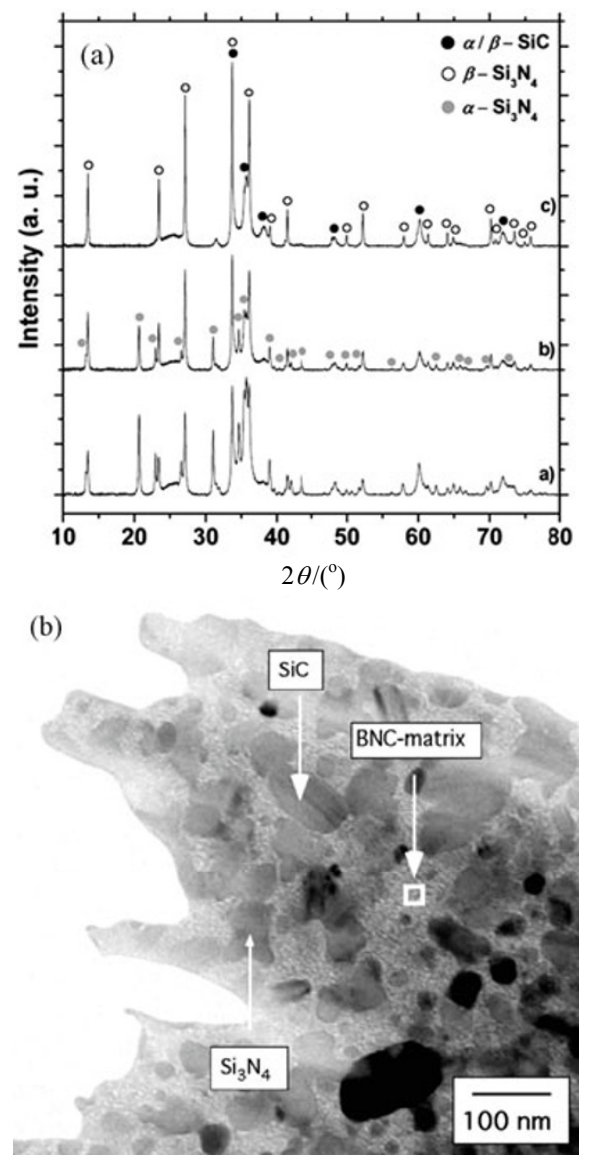

Fig. 10 XRD patterns (a) [29] and bright field image under TEM (b) [48] of the as-annealed Si-B-C-N ceramics.
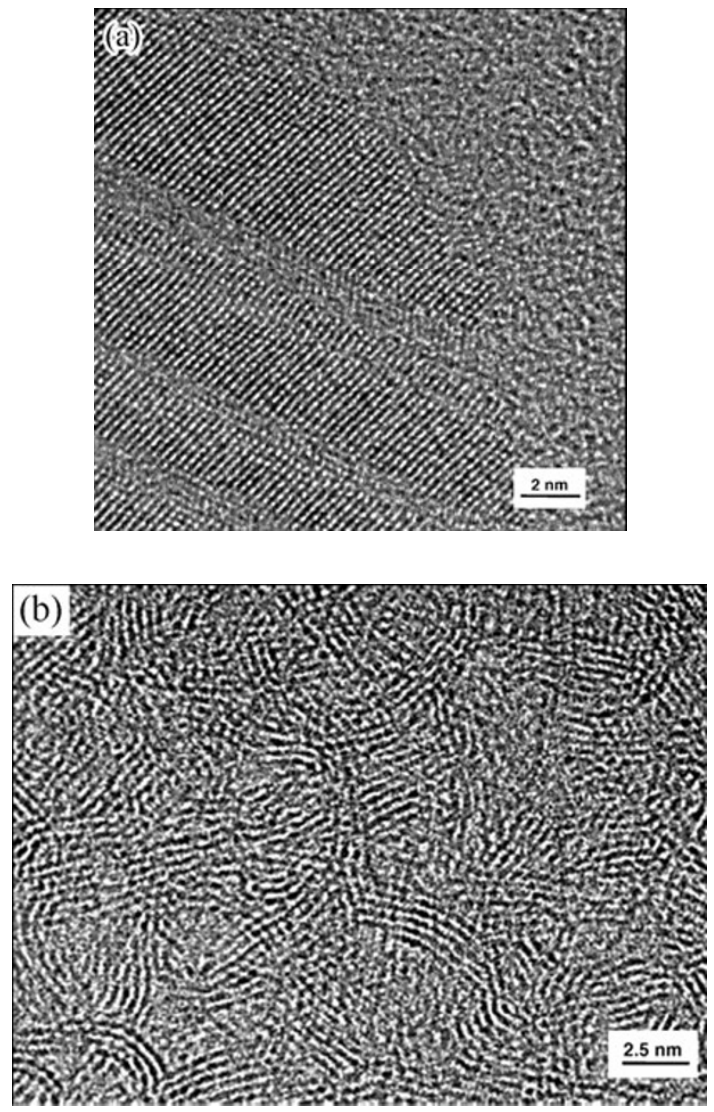

Fig. 11 The HRTEM image of the Si-B-C-N ceramic annealed at $1800{ }^{\circ} \mathrm{C} / \mathrm{Ar} / 5 \mathrm{~h}(\mathrm{a})$, and that of the $\mathrm{B}-\mathrm{N}-\mathrm{C}$ phase in the ceramic annealed at $2000^{\circ} \mathrm{C} / \mathrm{Ar} / 5 \mathrm{~h} \mathrm{(b)} \mathrm{[11].}$

The phase composition of the as-annealed nano Si-B-C-N ceramic may be varied, if raw materials or polymer synthetic process changes. One important case is that the as-annealed nano ceramic only consists of $\mathrm{SiC}$ and $\mathrm{B}-\mathrm{N}-\mathrm{C}, \mathrm{no} \mathrm{Si}_{3} \mathrm{~N}_{4}$. The results shown in Fig. 12 reveal the microstructure of this kind of nano Si-B-C-N ceramic. SiC has a grain size of about 100 $\mathrm{nm}$, and B-N-C has no fixed shape, lower crystallinity and a turbostratic structure. The phases are uniformly distributed in the ceramic. Research shows that this kind of ceramic may start to crystallize at a temperature lower than $1600{ }^{\circ} \mathrm{C}$ [30], lower than that of the nano ceramic consisting of $\mathrm{SiC}, \mathrm{Si}_{3} \mathrm{~N}_{4}$ and $\mathrm{B}-\mathrm{N}-\mathrm{C}$. However, thermogravimetric analysis reveals that this kind of Si-B-C-N ceramic has little weight loss even at $2100{ }^{\circ} \mathrm{C}$ [30], indicating a higher resistance to decomposition.

\subsection{Structure and its stability of the Si-B-C-N film prepared by reactive magnetron sputtering}

The Si-B-C-N film, prepared by the reactive 

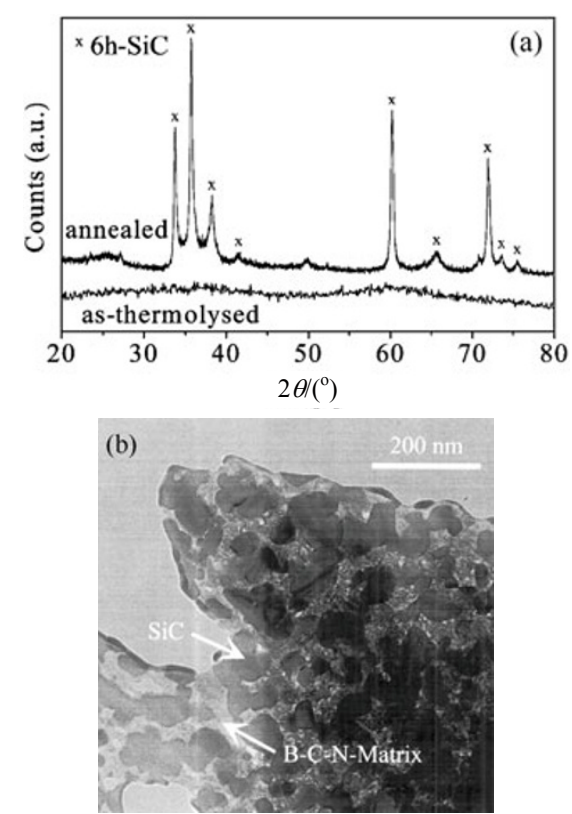

Fig. 12 The XRD spectrum (a) and bright field image under TEM (b) of the crystalline Si-B-C-N ceramic annealed at $1800{ }^{\circ} \mathrm{C} / \mathrm{N}_{2} / 3 \mathrm{~h}$, showing another kind of phase composition [59].

magnetron sputtering technique, generally has a smooth surface, a thickness of 1-5 $\mu \mathrm{m}$, an amorphous structure and a good structural stability, as revealed by the results presented in Fig. 13. It is found that the as-deposited Si-B-C-N film has a completely amorphous structure with high stability. The XRD spectra of the films have no identifiable diffraction peaks, coinciding with the results from HRTEM images. When annealing the film at $1600{ }^{\circ} \mathrm{C}$ in the argon atmosphere, it may not crystallize and still keep the amorphous structure, suggesting a high structural stability. The thermogravimetric analysis shows that the film may not lose weight at $1600{ }^{\circ} \mathrm{C}$ in an inert atmosphere, as suggested by the curve shown in Fig. 13b. At higher temperatures, sharp and severe decomposition and weight lose occur. It is evident that the as-deposited Si-B-C-N film has a lower decomposition temperature than that of the organic polymer derived bulk Si-B-C-N ceramic. This may be related to the homogeneity and the bonding states of various kinds of atoms, and further research is required in this subject. Additionally, the crystallized Si-B-C-N film mainly consists of $\mathrm{Si}_{3} \mathrm{~N}_{4}$, somewhat different from that of the polymer-derived nano Si-B-C-N ceramic.

\subsection{Structure of the Si-B-C-N ceramic prepared by mechanical alloying plus sintering}

To prepare $\mathrm{Si}-\mathrm{B}-\mathrm{C}-\mathrm{N}$ ceramic by the mechanical

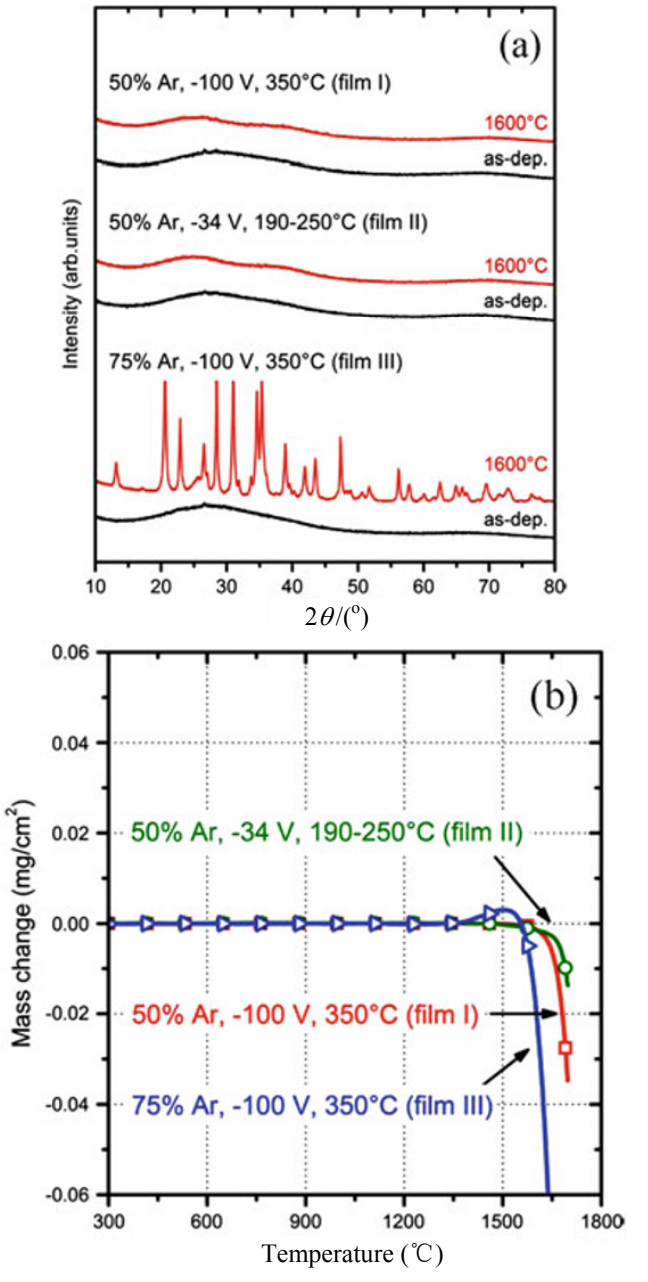

Fig. 13 XRD spectra of the as-deposited Si-B-C-N films and the films annealed at $1600{ }^{\circ} \mathrm{C}$ in argon (a), and thermogravimetric curves of Si-B-C-N films in helium up to $1700{ }^{\circ} \mathrm{C}$ (b) [56].

alloying plus sintering method, amorphous Si-B-C-N powder should be prepared by high-energy ball milling first, and the as-milled amorphous powder is then sintered at a high temperature under certain pressure to fabricate dense bulk ceramic. At present, the usually used ball mills include vibrating ball mill and planet ball mill. While the former produces a powder with crystallites or impurity [60], the latter normally generates a well amorphous Si-B-C-N powder [42]. From the XRD results displayed in Fig. 14, it is found that the powder prepared by vibrating ball mill generally has an amorphous structure, although containing weak diffraction peaks of $\mathrm{SiC}$ and zirconia. $\mathrm{SiC}$ crystallites come into being during the high energy ball milling process, and zirconia comes from the wear of zirconia balls or jars. In contrast, the powder, prepared by a planet ball mill with silicon nitride balls and jars, has no identifiable diffraction peaks, 


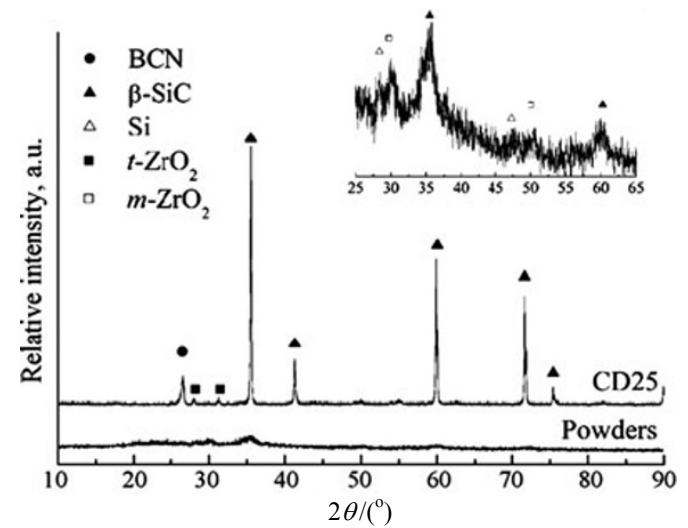

(a)

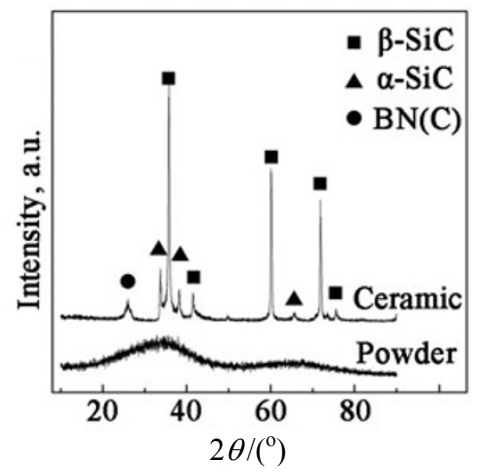

(b)

Fig. 14 The XRD spectra of the mechanically alloyed Si-B-C-N powders and sintered ceramics prepared by a vibrating ball mill with zirconia balls and jars (a) [60] or a planet ball mill with silicon nitride balls and jars (b) [37].

indicating a nice amorphous structure.

Sintered at high temperatures for $30 \mathrm{~min}$ in the nitrogen atmosphere, the XRD spectra of the prepared ceramics suggest that the amorphous structures have crystallized and the as-sintered bulk ceramics normally consist of $\mathrm{SiC}$ and $\mathrm{B}-\mathrm{N}-\mathrm{C}$, as revealed in Fig. 14. From the bright field images under TEM shown in Fig. 15, it is found that while the sintered ceramic with zirconia impurity has a SiC grain size of 200-500 nm, the ceramic prepared using the nice amorphous powder free from impurity just has a $\mathrm{SiC}$ grain size of about $100 \mathrm{~nm}$. Additionally, as compared to that in the former ceramic, B-N-C in the latter ceramic has a small size, a lower crystallinity and a more uniform distribution. It is inferred from the above results that the zirconia impurity may enhance atomic diffusion, favor crystallization and promote grain growth. The distribution and crystallinity variation of B-N-C may greatly contribute to the difference in ceramic microstructures.
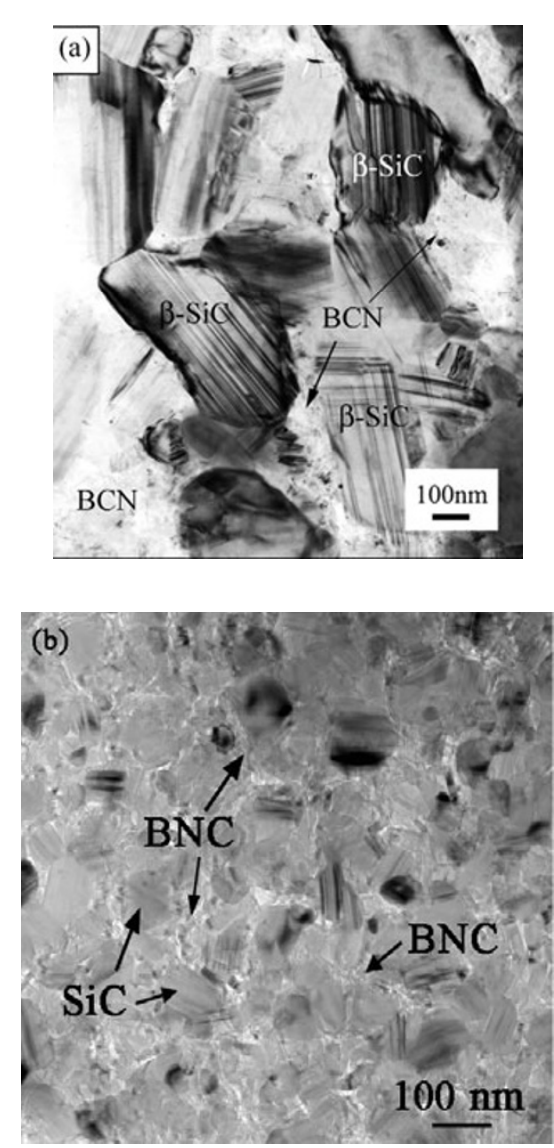

Fig. 15 The bright field images under TEM of the ceramics prepared using the impurity-containing (a) [26] and impurity-free (b) Si-B-C-N powder [27].

\section{Properties of $\mathrm{Si}-\mathrm{B}-\mathrm{C}-\mathrm{N}$ ceramic}

\subsection{Mechanical properties of $\mathrm{Si}-\mathrm{B}-\mathrm{C}-\mathrm{N}$ ceramic}

\subsubsection{Creep resistance of the polymer-derived Si-B-C-N bulk ceramic}

During the organic polymer pyrolyzing process, a large amount of gas will volatilize from the sample, because of the decomposition of the polymer precursor. As a result, large volume shrinkage and large weight loss will occur in the sample, resulting in the appearance of a large number of pores or even cracks in products. Thus, the preparation of dense bulk ceramics particularly with large dimensions and the evaluation of mechanical properties are difficult. Up to now, the mechanical property research of the polymer-derived bulk Si-B-C-N ceramic is limited to the creep resistance at elevated temperatures [13,61,62].

Figure 16 shows the creep curves of the polymer-derived amorphous and nanocrystalline $\mathrm{Si}-\mathrm{B}-\mathrm{C}-\mathrm{N}$ ceramics. It is found that when the amorphous ceramic is hold at $1400{ }^{\circ} \mathrm{C}$ under a pressure 
of $5 \mathrm{MPa}$ for $30 \mathrm{~h}$, the sample shows a deformation of about $1 \%$. At the same time, the deformation rate drops quickly. In the next $240 \mathrm{~h}$, the deformation rate always keeps a small value, and the total deformation of the sample is about $0.5 \%$. In contrast, although the nanocrystalline ceramic is hold at $1500{ }^{\circ} \mathrm{C}$ under 5 $\mathrm{MPa}$ for $270 \mathrm{~h}$, the total deformation of the sample is smaller than $0.1 \%$. It is believed that the different microstructures in these two kinds of ceramics lead to the variation of their creep behaviors. The amorphous ceramic has a metastable structure, which will crystallize and change into nano ceramic at high temperatures under a certain pressure. The crystallization process will be accompanied by various phenomena, such as nucleation, atomic diffusion, grain boundary sliding, and grain growth etc. These phenomena will lead to the change of ceramic microstructure and the macroscopic deformation of ceramic sample. When most of the amorphous structures turn into crystals, turbostratic B-N-C will retard the long-range diffusion of atoms, hinder the grain boundary sliding and depress the grain growth. As a result, the creep rate of the ceramic sample is greatly lowered and it becomes more difficult for further deformation.
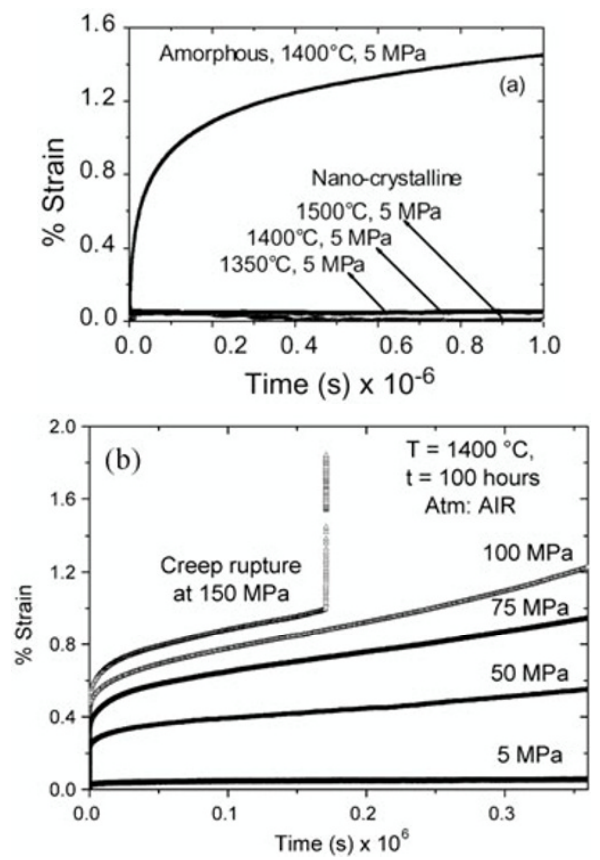

Fig. 16 Strain curves of amorphous and nano-crystalline Si-B-C-N ceramics as a function of time. (a) Strain curves of amorphous and nano-crystalline Si-B-C-N ceramics under a constant pressure of $5 \mathrm{MPa}$ [62]; (b) Strain curves of the nano-crystalline Si-B-C-N ceramic under various loads at $1400{ }^{\circ} \mathrm{C}$ in air [13].
In contrast, nanocrystalline $\mathrm{Si}-\mathrm{B}-\mathrm{C}-\mathrm{N}$ ceramic has a more stable structure, since it has been annealed at high temperatures for hours. The as-annealed ceramic consists of uniformly distributed nano grains, and no intergranular phase with low melting point exists in the grain boundary. Thus, the nanocrystalline ceramic has a better creep resistance and the ceramic sample exhibits a small deformation. Figure $16 \mathrm{~b}$ shows the creep curves of nanocrystalline Si-B-C-N ceramics. When the ceramic sample is hold at $1400{ }^{\circ} \mathrm{C}$ under a pressure of $50 \mathrm{MPa}$ for $100 \mathrm{~h}$, the total macroscopic deformation is smaller than $0.6 \%$, indicating an excellent creep resistance.

\subsubsection{Property of the polymer-derived Si-B-C-N fiber}

Because of its high structural stability and nice oxidation resistance, $\mathrm{Si}-\mathrm{B}-\mathrm{C}-\mathrm{N}$ fiber is expected to be a kind of high-performance ceramic fiber with potential applications in high temperature environments. Table 1 provides the mechanical, thermal and physical properties of Si-B-C-N fiber, SiC fiber and the user's requirements. Si-B-C-N fiber can be used at $1500{ }^{\circ} \mathrm{C}$ in air, which is superior to $\mathrm{SiC}$ fiber. In the argon atmosphere, Si-B-C-N fiber has a tensile strength of about $2.3 \mathrm{GPa}$ at $1500{ }^{\circ} \mathrm{C}$, and its elastic modulus at $1400{ }^{\circ} \mathrm{C}$ is $80 \%-90 \%$ of the value at room temperature. After exposure to air at $1500{ }^{\circ} \mathrm{C}$ for $50 \mathrm{~h}$, the tensile strength of the Si-B-C-N fiber is about $80 \%$ of the value at room temperature, but the retained strength of $\mathrm{SiC}$ fiber approaches to zero. The Si-B-C-N fiber also has a breaking elongation of about $0.7 \%-1.5 \%$, a good flexibility, a small density, a low thermal expansion coefficient and a nice resistance to melt silicon. These advantages make Si-B-C-N fiber the only kind of ceramic fiber that satisfies the requirements of users, who may adopt the fiber to fabricate ceramic or resin matrix composites applied at elevated temperatures.

\subsubsection{Mechanical property of the Si-B-C-N film prepared by reactive magnetron sputtering}

Vlček et al [23] prepared Si-B-C-N films on silicon or silicon oxide using the reactive magnetron sputtering method, and then evaluated their mechanical properties. As revealed in Fig. 17, employing the optimized technical parameters, the as-deposited film may have a Vickers hardness, an elastic modulus, and an elastic recovery of about $44 \mathrm{GPa}, 240 \mathrm{GPa}$, and $82 \%$, respectively. Among various factors, the bias voltage and the temperature of substrate have stronger influence on these mechanical properties. The compressive stress between the film and the substrate 
Table 1 Performance comparison between Si-B-C-N fiber and several typical SiC fibers, as well as the requirements of potential users [17,63-65]

\begin{tabular}{|c|c|c|c|c|c|}
\hline Properties & $\begin{array}{c}\text { Requirements } \\
\text { of the European } \\
\text { Turbine Manufacturers }\end{array}$ & $\begin{array}{c}\mathrm{SiBN}(\mathrm{C}) \\
\text { Bayer Uni } \\
\text { Bonn } \\
\end{array}$ & $\begin{array}{c}\mathrm{SiC} \\
\text { Dow } \\
\text { Corning } \\
\end{array}$ & $\begin{array}{c}\mathrm{SiC} \\
\text { (Hi-Nicalon) } \\
\text { Nippon Carbon } \\
\end{array}$ & $\begin{array}{c}\mathrm{SiCTiO} \\
\text { (Thyranno Lox E) Ube } \\
\text { Industries } \\
\end{array}$ \\
\hline Oxygen content ( $\%$ in weight) & - & 1.0 & 0.2 & 0.8 & 0.3 \\
\hline Microstructure & - & \multicolumn{2}{|c|}{ AmorphousCrystalline } & 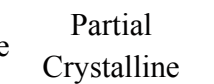 & Crystalline \\
\hline Max. temperature usable in air, ${ }^{\circ} \mathrm{C}$ & $1500-2000$ & 1500 & 1300 & 1200 & 1000 \\
\hline \multicolumn{6}{|l|}{ Tensile strength } \\
\hline at room temperature (RT), GPa & 3.0 & $3-4$ & $3-4$ & 3 & ca. 3.2 \\
\hline at $1400{ }^{\circ} \mathrm{C}$ in $\mathrm{Ar}$ ( $\%$ of RT-value) & - & 95 & 95 & 70 & 95 \\
\hline at $1500{ }^{\circ} \mathrm{C}$ in $\mathrm{Ar}, \mathrm{GPa}$ & 2.5 & 2.3 & - & - & - \\
\hline \multicolumn{6}{|l|}{ Strength after exposure to air ( $\%$ of RT-value) } \\
\hline at $1300{ }^{\circ} \mathrm{C}$ for $100 \mathrm{~h}$ & - & - & - & 23 & 55 \\
\hline at $1500{ }^{\circ} \mathrm{C}$ for $50 \mathrm{~h}$ & - & 80 & - & 0 & - \\
\hline \multicolumn{6}{|l|}{ E-modulus } \\
\hline at $\mathrm{RT}, \mathrm{GPa}$ & 300 & $200-350$ & 420 & 300 & 200 \\
\hline at $1400{ }^{\circ} \mathrm{C}$ in $\mathrm{Ar}(\%$ of RT-value $)$ & 83 & $80-90$ & - & 70 & - \\
\hline Breaking elongation, $\%$ & 1.0 & $0.7-1.5$ & 0.6 & 1.0 & 1.5 \\
\hline Creep parameter ${ }^{*}$ & $>0.4$ & 0.8 & 0.4 & 0.1 & 0.7 \\
\hline Subcritical crack growth & - & No & Yes & No & Yes \\
\hline Coefficient of thermal expansion, $\times 10^{-6} / \mathrm{K}$ & $3-5$ & 3.5 & 4 & 3.3 & 4.5 \\
\hline Thermal conductivity, $\mathrm{W} /(\mathrm{m} \cdot \mathrm{K})$ & - & $>3$ & 46 & 5 & 64 \\
\hline Resistance to molten silicon & - & Yes & No & No & No \\
\hline Density, $\mathrm{g} / \mathrm{cm}^{3}$ & $<5$ & 2 & 3.1 & 2.74 & 2.5 \\
\hline Diameter, $\mu \mathrm{m}$ & $10-150$ & $8-14$ & 10 & 14 & 12 \\
\hline Flexibility & Good & Good & Medium & Good & Good \\
\hline
\end{tabular}

: Bend-stress-relaxation measurements at $1400^{\circ} \mathrm{C}$
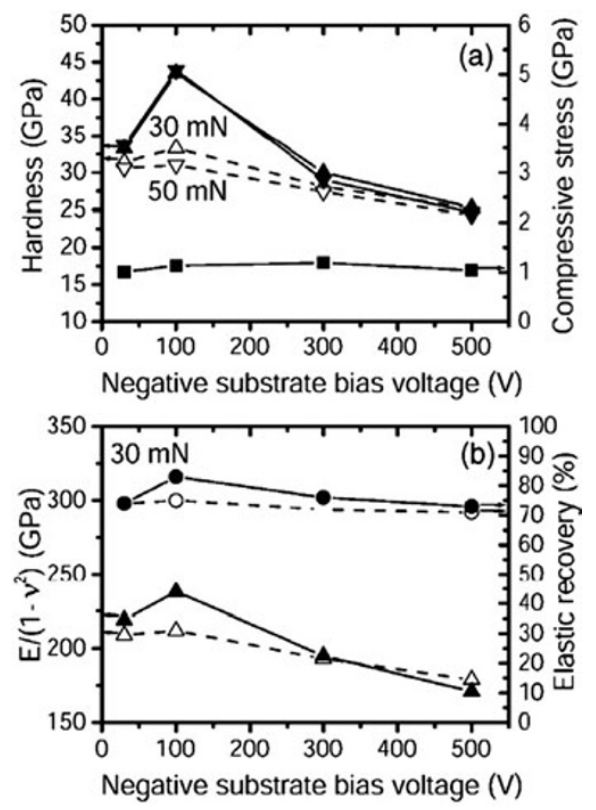

Fig. 17 Mechanical properties of the Si-B-C-N films prepared using a C-S-B (20:60:20\%) target at various negative substrate bias voltages in a $50 \%$ $\mathrm{N}_{2}+50 \%$ Ar gas mixture for $T_{\mathrm{s}}=350{ }^{\circ} \mathrm{C}$ (full symbols) and $T_{\mathrm{s}}=180-250{ }^{\circ} \mathrm{C}$ (empty symbols) [23]. is about $1 \mathrm{GPa}$, which is slightly affected by the variation of preparation conditions. A small compressive stress indicates a nice lattice match at the interface, and the film is not easy to flake.

\subsubsection{Mechanical property of the Si-B-C-N ceramic prepared by mechanical alloying plus sintering}

By the mechanical alloying plus sintering method, it is easy to prepare dense bulk ceramic particularly with large dimensions, and various mechanical properties can be conveniently evaluated. This is superior to the organic polymer pyrolysing route. The ceramic sample prepared by this method generally has a diameter of $30-50 \mathrm{~mm}$, with a bulk density of $2.5-2.8 \mathrm{~g} / \mathrm{cm}^{3}$. The bulk density approaches to that of the polymer-derived bulk Si-C-N ceramics or the magnetron sputtered Si-B-C-N films. Table 2 lists the room-temperature and high-temperature mechanical properties of the ceramics hot pressed at $1800{ }^{\circ} \mathrm{C}, 1850{ }^{\circ} \mathrm{C}$ or $1900{ }^{\circ} \mathrm{C}$ under a pressure of $40 \mathrm{MPa}$ or $80 \mathrm{MPa}$ in the nitrogen or argon atmosphere for $30 \mathrm{~min}$. Using the powder prepared by a single-step-milling route $[27,66]$, the $\mathrm{CS} 1900$ ceramic sintered at $1900{ }^{\circ} \mathrm{C}$ has 
Table 2 Mechanical properties of the bulk Si-B-C-N ceramics, hot pressed at $1850{ }^{\circ} \mathrm{C}$ or $1900{ }^{\circ} \mathrm{C}$ under a pressure of $40 \mathrm{MPa}$ in the nitrogen atmosphere for $30 \mathrm{~min}[26,27,67]$.

\begin{tabular}{|c|c|c|c|c|c|c|}
\hline \multirow{2}{*}{ Ceramic sample } & \multicolumn{3}{|c|}{ Flexural strength $(\mathrm{MPa})$} & \multirow{2}{*}{$\begin{array}{l}\text { Young's } \\
\text { Modulus } \\
(\mathrm{GPa})\end{array}$} & \multirow{2}{*}{ Fracture toughness $\left(\mathrm{MPa} \cdot \mathrm{m}^{1 / 2}\right)$} & \multirow{2}{*}{ Vickers hardness (GPa) } \\
\hline & RT & $1000{ }^{\circ} \mathrm{C}$ & $1400{ }^{\circ} \mathrm{C}$ & & & \\
\hline CS1850 & $191.7 \pm 20.7$ & - & - & $107.9 \pm 9.5$ & $1.80 \pm 0.07$ & $2.44 \pm 0.31$ \\
\hline CS1900 & $312.8 \pm 5.2$ & $287.2 \pm 15.5$ & $225.3 \pm 15.1$ & $136.3 \pm 17.8$ & $3.31 \pm 0.02$ & $4.17 \pm 0.50$ \\
\hline CD1900 & $423.4 \pm 43.0$ & $375.4 \pm 10.7$ & $260.4 \pm 15.7$ & $134.6 \pm 13.5$ & $3.09 \pm 0.05$ & $3.89 \pm 0.43$ \\
\hline CA1800 & $421.9 \pm 27.3$ & - & - & $174.1 \pm 10.2$ & $3.40 \pm 0.15$ & $12.74 \pm 0.32$ \\
\hline CN1800 & $526.8 \pm 10.4$ & - & - & $222.1 \pm 27.7$ & $5.25 \pm 0.20$ & $11.63 \pm 0.49$ \\
\hline $1900^{\circ} \mathrm{C} / 80 \mathrm{MPa}$ & $331.1 \pm 40.5$ & - & - & $139.4 \pm 16.0$ & $2.7 \pm 0.4$ & $4.7 \pm 0.2$ \\
\hline
\end{tabular}

room-temperature flexural strength, Young's modulus, fracture toughness and Vickers hardness of about 312.8 $\mathrm{MPa}, 136.3 \mathrm{GPa}, 3.31 \mathrm{MPa} \cdot \mathrm{m}^{1 / 2}$, and 4.17 $\mathrm{GPa}$, respectively. The flexural strength and Young's modulus are approximately one-third of those of the hot-pressed SiC ceramics, and the fracture toughness is slightly lower than that of the latter. At $1000{ }^{\circ} \mathrm{C}$ and $1400{ }^{\circ} \mathrm{C}$ in air, the ceramic sample still has a flexural strength of about 287.2 $\mathrm{MPa}$ and 225.3 $\mathrm{MPa}$, respectively. When hot pressing the powder prepared by a two-step-milling route at $1900{ }^{\circ} \mathrm{C}$ under $40 \mathrm{MPa}$ for $30 \mathrm{~min}$ [27], the obtained CD1900 ceramic possesses a room-temperature flexural strength and Young's modulus of about 423.4 MPa and 134.6 GPa, respectively. The relatively higher flexural strength and lower Young's modulus indicates a favourable resistance to thermal shock. When aluminum was added in raw powders, the CA1800 or CN1800 ceramic hot pressed at $1800 \mathrm{oC}$ has a flexural strength of about 400-550 MPa. However, the Si-B-C-N ceramic free from any impurity or additive and hot pressed at $1900{ }^{\circ} \mathrm{C} / 80 \mathrm{MPa}$ just has a flexural strength of about $331.1 \mathrm{MPa}$. Obviously, the mechanically alloyed Si-B-C-N powder is hard to densify, and the introduction of zirconia or aluminum may promote its sintering and hence improve the room temperature mechanical properties of the hot pressed Si-B-C-N ceramic.

\subsection{Oxidation resistance of the $\mathrm{Si}-\mathrm{B}-\mathrm{C}-\mathrm{N}$ ceramic}

\subsubsection{Oxidation resistance of the polymer-derived Si-B-C-N ceramic}

The results from thermogravimetric analysis indicate that the polymer-derived Si-B-C-N ceramic has an oxidation resistance even better than $\mathrm{SiC}$ or $\mathrm{Si}_{3} \mathrm{~N}_{4}$ ceramic, as revealed by the results shown in Fig. 18a. When heating ceramic fragments in an air flow, the oxidation of $\mathrm{SiC}$ and $\mathrm{Si}_{3} \mathrm{~N}_{4}$ occurs at about $1050{ }^{\circ} \mathrm{C}$ and $1200{ }^{\circ} \mathrm{C}$, respectively. However, Si-B-C-N ceramic
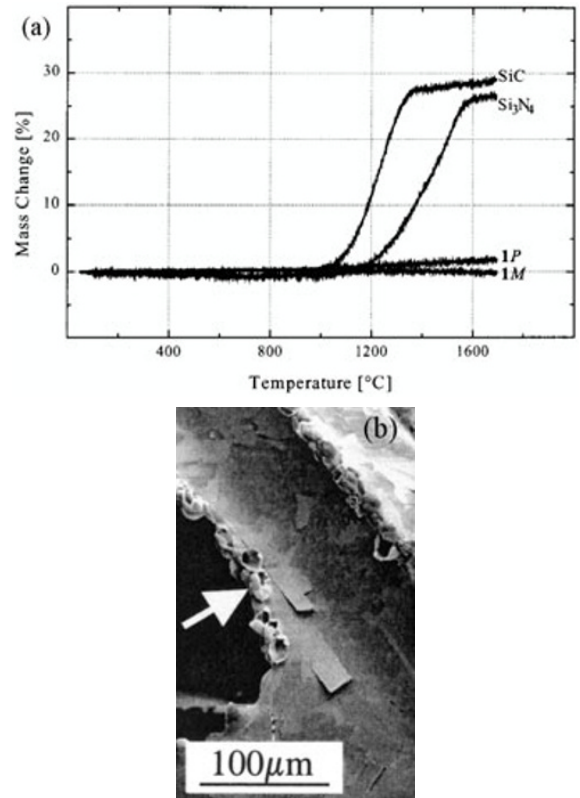

Fig. 18 Thermogravimetric curves of Si-B-C-N ceramic powders tested in air [10] (a), and surface morphology of the Si-B-C-N bulk ceramic oxidized at $1500{ }^{\circ} \mathrm{C}$ in air for $24 \mathrm{~h} \mathrm{(b)} \mathrm{[67].}$

has little weight change even at $1700{ }^{\circ} \mathrm{C}$. It is inferred that the excellent oxidation resistance of this kind of ceramic may be due to the complex structure of the oxidation film formed on the ceramic surface during heating process, and this has been partially confirmed by the experimental results on Si-B-C-N bulk ceramic and ceramic fiber. The image shown in Fig. $18 \mathrm{~b}$ is the surface morphology of the ceramic oxidized at $1500{ }^{\circ} \mathrm{C}$ for $24 \mathrm{~h}$. It is found that bubbles only appear at the edges of the ceramic particle, while on the flat surface, the oxidation film is uniform and unbroken. The results from Raman analysis reveal that the oxidation products in the edges mainly contain cristobalite and that in the flat surface still have an amorphous structure. The inclusion of boron atoms in the oxidation film may retard its crystallization. 
The image in Fig. 19a displays the cross section of a Si-B-C-N fiber oxidized at $1500{ }^{\circ} \mathrm{C}$ in air for $2 \mathrm{~h}$. The oxidation film on this fiber is uniform and compact, with a thickness of about $2 \mu \mathrm{m}$. Under TEM, the oxidation film is found to have a quite dense multilayer structure, as suggested by the image shown in Fig. 19b. The outer layers have a large content of silicon oxide, and are easy to crystallize. The inner layers are mainly composed of amorphous $\mathrm{Si}-\mathrm{B}-\mathrm{C}-\mathrm{N}-\mathrm{O}$ and various kinds of boron nitride. Boron nitride is rich in inner layers and lack in outer layers. At high temperatures in air, boron and nitrogen atoms in the surface layer of the ceramic may form boron nitride. While boron nitride in inner layers is hard to be oxidized, that in outer layers is easy to be oxidized and the oxidation products are easy to volatilize. On the other hand, the non-volatilized boron oxide may dissolve in silicon

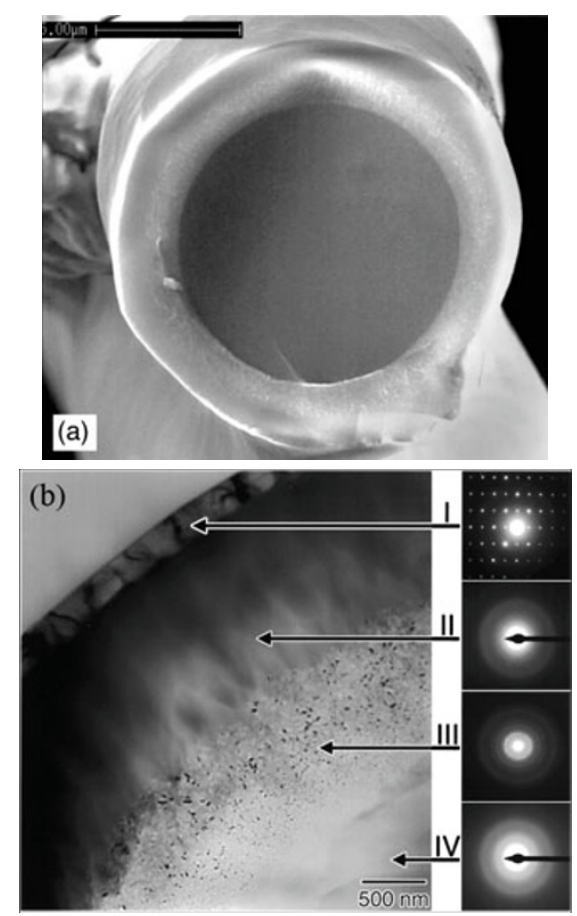

Fig. 19 Cross section of the Si-B-C-N ceramic fiber oxidized at $1500{ }^{\circ} \mathrm{C}$ in air for $2 \mathrm{~h}$ (a), and TEM image of a cross section (along fiber axis) of the oxidized portion of a fiber heated at $1500{ }^{\circ} \mathrm{C}$ for $2 \mathrm{~h}$ in air, indicating four distinct zones with their corresponding electron diffraction patterns: (I) surface layer of $\alpha$-cristobalite with diffraction pattern ([100] zone axis); (II) homogeneous layer of amorphous silica; (III) mixed layer of SiBCNO glass with $\mathrm{BN}$ precipitates, diffraction pattern shows hexagonal $\mathrm{BN}$ reflections with strong contribution of (0002) planes; (IV) core of fiber, which remained unchanged (b) [68]. oxide and form a complex structure in the oxide film. This film may have a proper viscosity and perfectly cover the ceramic surface, retarding the diffusion of oxide atoms and preventing the further oxidation of the ceramic.

\subsubsection{Oxidation resistance of the Si-B-C-N film prepared by reactive magnetron sputtering}

The Si-B-C-N film prepared by the reactive magnetron sputtering technique also possesses a good oxidation resistance, as reveled by the thermogravimetric curve displayed in Fig. 20. It is found that the Si-B-C-N film sputtered with the $\mathrm{B}_{4} \mathrm{C}-\mathrm{Si}$ target shows extremely high (up to $1400{ }^{\circ} \mathrm{C}$ ) and very high (up to $1600{ }^{\circ} \mathrm{C}$ ) oxidation resistance. However, the oxidation of the $\mathrm{SiC}$ substrate starts at temperatures above $1100{ }^{\circ} \mathrm{C}$. Further research indicates that the mass change of the film after oxidation in air up to $1700{ }^{\circ} \mathrm{C}$ is caused by the formation of oxide layer on the film surface [69]. The oxide layer is amorphous, has a thickness of about 1 $\mu \mathrm{m}$, and mainly consists of almost stoichiometric $\mathrm{SiO}_{2}$, with a small content of boron, nitrogen and carbon. It is inferred that the inclusion of boron in the surface layer may greatly contribute to the maintenance of the amorphous state of the oxide layer, and this is similar to that of the oxidation layer on poly-derived Si-B-C-N bulk ceramic or ceramic fiber.

\subsubsection{Oxidation resistance of the Si-B-C-N ceramic prepared by mechanical alloying plus sintering}

The oxidation of the bulk Si-B-C-N ceramic, prepared by the mechanical alloying plus sintering method, is also evaluated by the thermogravimetric analysis in an air flow with a heating rate of $10{ }^{\circ} \mathrm{C} / \mathrm{min}$, as shown in

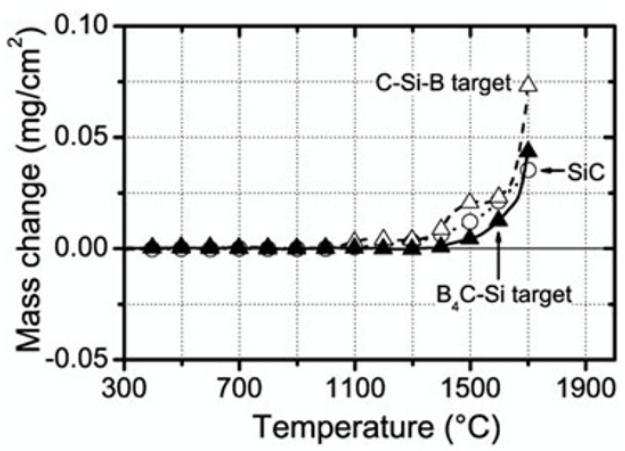

Fig. 20 Thermogravimetric analysis of asdeposited Si-B-C-N films in a pure air at a heating rate of $10{ }^{\circ} \mathrm{C} / \mathrm{min}$. The films were prepared using a C-Si-B $(5: 75: 20 \%)$ or $\mathrm{B}_{4} \mathrm{C}-\mathrm{Si}(25: 75 \%)$ target in a $50 \% \mathrm{~N}_{2}+50 \%$ Ar gas mixture. For comparison, the data obtained for the $\mathrm{SiC}$ substrate are also presented [69]. 
Fig. 21. The ceramic sample CS2H1900 shows little mass change up to $1500{ }^{\circ} \mathrm{C}$, indicating a great oxidation resistance in such conditions. After oxidized at $1200{ }^{\circ} \mathrm{C}$ in dry air for $5 \mathrm{~h}$ or $85 \mathrm{~h}$, the oxidation layer on the ceramic surface is coarse, and has lots of cracks on its surface [70]. The layer has a thickness of about 5-10 $\mu \mathrm{m}$, and mainly contains crystalline $\mathrm{SiO}_{2}$, with a small content of nitrogen and carbon, and little content of boron. These are very different from that of the oxidation layers on polymer-derived or as-deposited Si-B-C-N ceramics. Probably, the crystallization and the little boron content in the oxidation layer are attributed to the crystallized structure of the as-sintered ceramic and the inhomogeneity of various atoms. Further research is required on the relationship between the microstructure and the oxidation resistance of the as-sintered Si-B-C-N bulk ceramic. Additionally, recent research shows that the addition of $\mathrm{AlN}$ or $\mathrm{ZrO} 2$ in raw powders may reduce the oxidation resistance of the hot pressed Si-B-C-N ceramic at the temperature range of about $1000-1400 \mathrm{oC}$, and these results will be further studied and published in another article.

\subsection{Electrical and optical properties of Si-B-C-N ceramic}

\subsubsection{Electrical property of the polymer-derived Si-B-C-N ceramic}

The electrical conductivity of the polymer-derived Si-B-C-N ceramic may dramatically change before and after being annealed at high temperatures, as indicated in Fig. 22. By pyrolyzing poly(boro)silazane at $1000{ }^{\circ} \mathrm{C}$ in the argon atmosphere for hours, the prepared amorphous Si-B-C-N ceramic has a

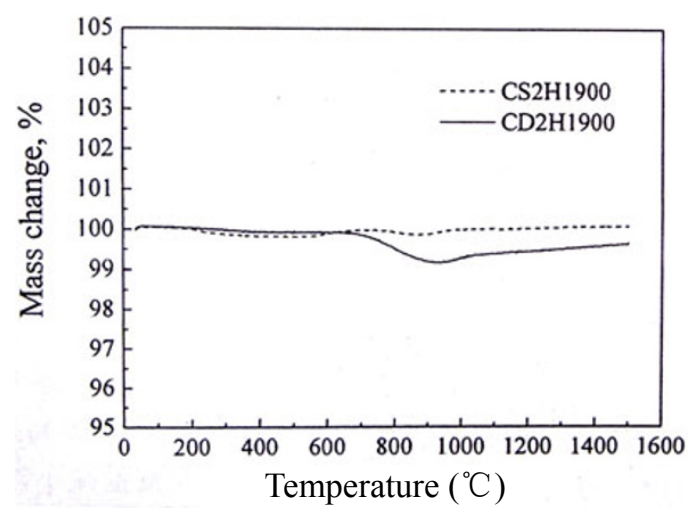

Fig. 21 Thermogravimetric curve of CS2H1900 and CD2H1900 ceramics in an air flow with a heating rate of $10{ }^{\circ} \mathrm{C} / \mathrm{min}[70]$.

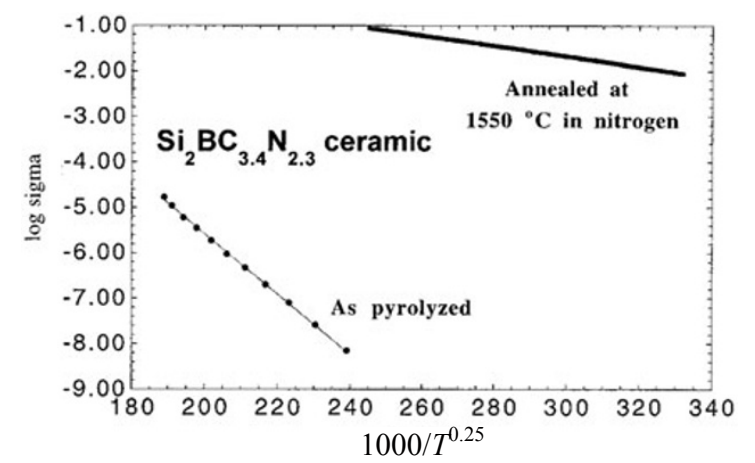

Fig. 22 Conductivities of as-pyrolyzed and as-annealed Si-B-C-N ceramics as functions of temperature [71].

conductivity of about $10^{-8} \Omega^{-1} \cdot \mathrm{cm}^{-1}$. This value is about four orders larger than that of as-pyrolyzed Si-C-N ceramic, and this may be related to the doping of boron atoms or the formation of crystallites in the ceramic. When annealed the amorphous Si-B-C-N ceramic at $1550{ }^{\circ} \mathrm{C}$ in the nitrogen atmosphere for $12 \mathrm{~h}$, its conductivity is quickly increased to about $10^{-1} \Omega^{-1} \cdot \mathrm{cm}^{-1}$. The rapid conductivity increase may be attributed to the loss of nitrogen during the annealing process [71]. The variation of the conductivity with the change of temperature before and after annealing fits the VRH model, indicating that the ceramics all have amorphous structures, and the as-annealed ceramic may contain a large amount of unsaturated bonds. Because of the excellent structural stability and the electric conductivity at high temperatures, polymer-derived Si-B-C-N ceramic may be widely used in microelectronic circuits applied at elevated temperatures, such as filament, conductive coating or semiconductor device based on PN junction.

\subsubsection{Electrical and optical properties of the Si-B-C-N film prepared by reactive magnetron sputtering}

The results presented in Fig. 23 reveal the influence of the nitrogen content in the air flow on the electric resistivity and the photonic gap of the as-deposited Si-B-C-N film. When the air flow contains no nitrogen, the electrical resistivity of the film is about $0.209 \Omega \cdot \mathrm{m}$. With the increase of the nitrogen content, the electrical resistivity of the deposited film shows a rapid rise. When the nitrogen content is $20 \%$, the electrical resistivity is dramatically enhanced to $1.4 \times 10^{6} \Omega \cdot \mathrm{m}$. It is also found that when the nitrogen content is higher than $30 \%$, the electrical resistivity may be much larger 

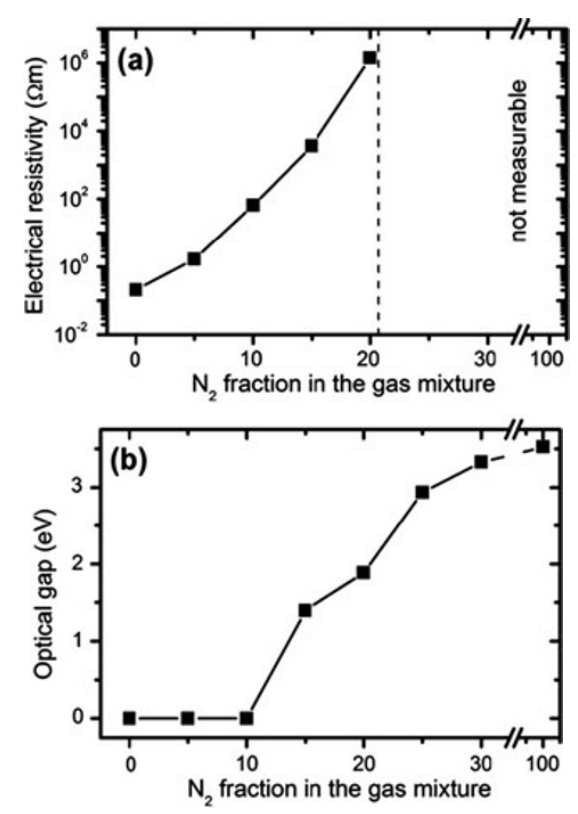

Fig. 23 Influence of the nitrogen content in airflow on the electrical resistivity (a) and the optical gap (b) of Si-B-C-N ceramic film [72].

than $10^{8} \Omega \cdot \mathrm{m}$ [72]. These results suggest that the as-deposited Si-B-C-N film with small nitrogen content may be a semiconductor, while a large amount of nitrogen is included, the film may turn into an insulator. Research shows that the optical gap of the as-deposited Si-B-C-N film also greatly relies on the nitrogen content in the air flow, as shown in Fig. 23b. When the nitrogen content is smaller than $10 \%$, the optical gap of the prepared film is nearly zero. When nitrogen content is higher than $10 \%$, the optical gap of the film starts to increase, and the value reaches to $2-3 \mathrm{eV}$ when the nitrogen content is between $20 \%-30 \%$. Results from theoretical calculation suggest that the electrical and optical property variation of the as-deposited film may be related to the doping of nitrogen atoms, which may split the valence bond of atoms. Additionally, the Si-B-C-N film also exhibits other physical or thermal properties, such as photoluminescence, small thermal conductivity and thermal expansion coefficient [24].

\section{Potential applications of Si-B-C-N ceramics}

\subsection{Applications of the polymer-derived Si-B-C-N ceramic}

Since polymer precursors have a proper viscosity when they are heated, various common shaping technics can be employed here, such as casting, injection molding, pressure forming, tape casting, drawing, dipping, painting and impregnation, as indicated in Fig. 24. By shaping and then pyrolyzing the organic polymer precursor, many kinds of products can be prepared, including bulk ceramic, ceramic fiber, porous ceramic, ceramic coating, ceramic matrix composite, and components with various shapes. Because of the especially high structural stability, nice oxidation resistance, high creep resistance, and other outstanding properties, these products can be used to fabricate high-performance materials or components applied at elevated temperatures, such as the nose cone in high-speed aerocraft, the brake block in high-speed vehicle, the filter or absorber in water or gas purification installation, and the micro-sized components in microdevice, micromotor or microcircuit [20]. Thus, the polymer-derived Si-B-C-N ceramic may be widely used in transportation, aerocraft, energy, information, microelectronics, environment, etc.

Currently, most of the products prepared by the polymer pyrolyzing route are bulk ceramics or ceramic fibers. The bulk ceramic has a diameter of about $1 \mathrm{~cm}$, as shown in Fig. 25a. Since polymer pyrolyzing will produce a large amount of gas, and large weight loss and volume shrinkage will occur in the precursor, the preparation of ceramic sample especially with large dimensions is difficult. Although a pressure-assisted pyrolyzing method is developed in recent years [52], the size of the bulk ceramic is still not increased considerably. Micro component with a dimension of hundreds of microns can also be fabricated by this method, as displayed in Fig. 25b. This kind of component can be applied in micro devices at high

Shaping of the precursors:

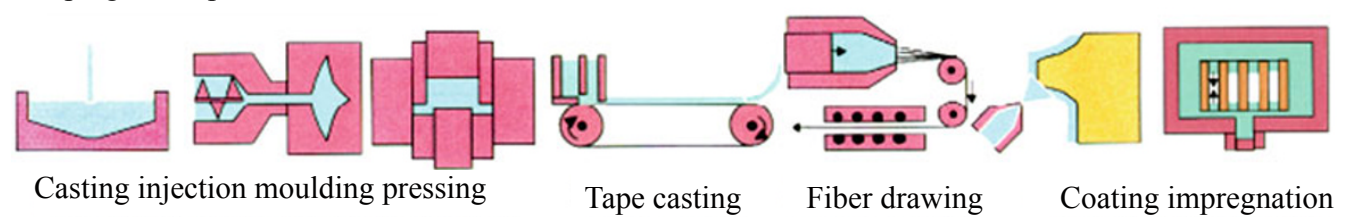

Fig. 24 Techniques applicable to the shaping of organic polymer precursors [20]. 

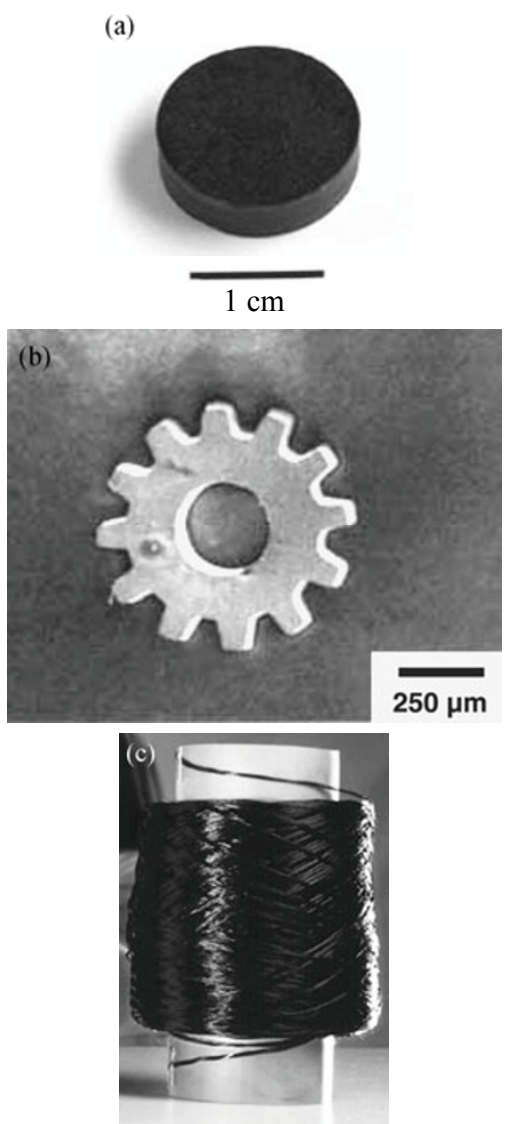

Fig. 25 The Si-B-C-N bulk ceramic (a) [12], micrometer gear (b) [17] and ceramic fiber (c) [65], prepared by the organic polymer pyrolyzing method.

temperatures, such as micro mechanical device, micro electronic circuit, micro turbine, and micro sensor etc. Additionally, pyrolyzing organic polymer can also produce a porous ceramic, which can be applied in the field of adsorption or filtration at high temperatures. Figure $25 \mathrm{c}$ displays the Si-B-C-N ceramic fiber prepared by the melt spinning method. The fiber generally has a smooth surface and a diameter of 8-14 $\mu \mathrm{m}$. At $1500{ }^{\circ} \mathrm{C}$ or even higher temperatures in air, the Si-B-C-N fiber has a large tensile strength, high structural stability, and excellent oxidation resistance [65]. Therefore, the Si-B-C-N fibers have great practical values at high temperatures.

Research shows that adding reinforcing phases into polymer precursor may further increase the high-temperature mechanical properties of Si-B-C-N ceramics. Impregnating the melt polymer precursor into carbon-fiber woven fabrics and then pyrolyzing it at high temperatures will produce a $\mathrm{C}_{\mathrm{f}} / \mathrm{Si}-\mathrm{B}-\mathrm{C}-\mathrm{N}$ ceramic matrix composite, whose appearance is displayed in Fig. 26a [19]. Substituting the melt precursor with a kind of SiC-whisker-included polymer,
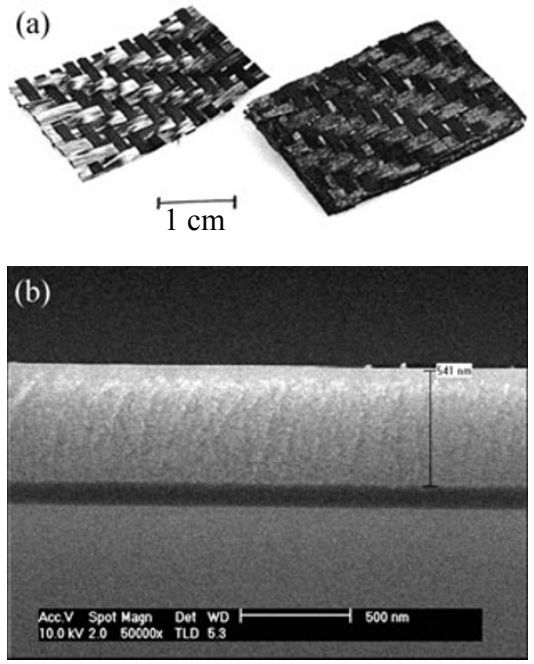

Fig. 26 Carbon fiber fabrics before (left) and after resin-transfer-molding and thermolysis (right) (a) [8], and the cross section morphology of the Si-B-C-N coating prepared by spinning and pyrolyzing technology on the surface of $\mathrm{SiO}_{2}-\mathrm{Si}$ (b) [74].

the product will be a $\mathrm{C}_{\mathrm{f}} / \mathrm{SiC}_{\mathrm{p}} / \mathrm{Si}-\mathrm{B}-\mathrm{C}-\mathrm{N}$ composite [73]. As compared with Si-B-C-N ceramic, these ceramic matrix composites generally have better structural stability, mechanical properties and creep resistance at high temperatures. They possess ductile fracture, no matter at room temperature, at elevated temperature, or even they are annealed at high temperatures for hours. Thus, they may be applied in high-performance brake sheet, or thermal protection materials on high-speed aircrafts. Employing dipping or painting method, one can also prepare Si-B-C-N coatings on carbon fibers or metals, as indicated in Fig. 26b. Since Si-B-C-N ceramic has nice structural stability and oxidation resistance, the coatings may be used as oxidation resistant or corrosion resistant materials.

\subsection{Applications of the Si-B-C-N film prepared by reactive magnetron sputtering}

At present, the Si-B-C-N film is mainly prepared by the reactive magnetron sputtering method. This method employs a simple operation, causes little pollution, and is able to produce ceramic films on various kinds of substrates. The as-deposited film has a smooth surface and a uniform thickness, as shown in Fig. 27. Research reveals that the film has a high structural stability, good oxidation resistance, high hardness, small thermal expansion coefficient, and small compressive stress on the interface [23]. Additionally, the film also 


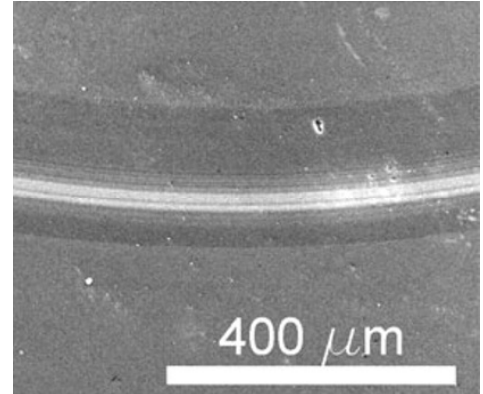

Fig. 27 SEM image of the alumina ball track on the Si-B-C-N film deposited by the reactive direct current magnetron co-sputtering on the surface of silicon [36].

has the characteristic of semiconductor, photoluminescence or light transmission [24]. The Si-B-C-N film may be applied in high-temperature photoelectron circuit, communication or control device.

\subsection{Applications of the $\mathrm{Si}-\mathrm{B}-\mathrm{C}-\mathrm{N}$ ceramic prepared by mechanical alloying plus sintering}

The latest findings show that the Si-B-C-N bulk ceramic prepared by the mechanical alloying plus sintering method has a microstructure similar to that of some polymer-derived nano Si-B-C-N ceramics. However, the former has a simple preparation process, a higher relative density and a larger dimension, as displayed in Fig. 28. The diameter, thickness, relative density and room-temperature fracture strength of the ceramic sample is about $30 \mathrm{~mm}, 4.5 \mathrm{~mm}, 91 \%$, and $331 \mathrm{MPa}$, respectively [37]. The image in Fig. 29 is the fracture morphology of the $\mathrm{C}_{\mathrm{f}} / \mathrm{Si}-\mathrm{B}-\mathrm{C}-\mathrm{N}$ ceramic matrix composite, prepared by hot pressing the chopped-carbon-fibers-mixed Si-B-C-N powder at $1800{ }^{\circ} \mathrm{C}$ for $30 \mathrm{~min}$. The composite manifests a ductile

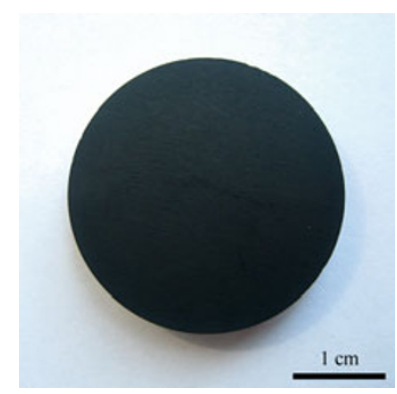

Fig. 28 Digital image of the bulk ceramic prepared from the mechanically alloyed Si-B-C-N powder [37]..

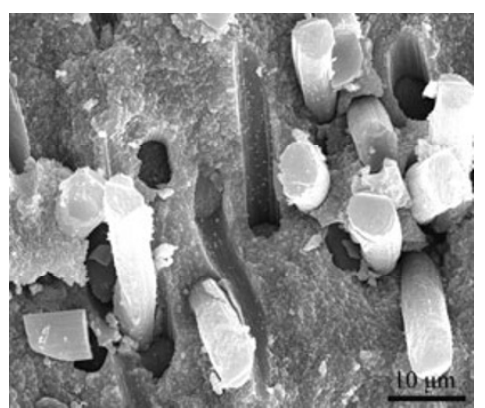

Fig. 29 Fractograph of the $\mathrm{C}_{\mathrm{f}} / \mathrm{Si}-\mathrm{B}-\mathrm{C}-\mathrm{N}$ ceramic matrix composite prepared by hot pressing the Si-B-C-N powder mixed with chopped carbon fiber at $1800{ }^{\circ} \mathrm{C}$ for $30 \mathrm{~min}$ [75].

fracture mode, a nice resistance to thermal shock and to the erosion of high-temperature airflow. Thus, it is potentially used to fabricate structural or thermal protection components, serving at elevated temperature range.

\section{Conclusions and outlook}

Si-B-C-N ceramic attracts great attention in the past twenty years or so, because of its special structures and outstanding properties. Currently, the ceramic is mainly prepared by organic polymer pyrolyzing route, reactive magnetron sputtering and mechanical alloying plus sintering method. While most researchers focus on the polymer pyrolyzing route, the reactive magnetron sputtering and mechanical alloying plus sintering methodsare only developed in recent years, thus the studies are still in their infancy. Much research work on the Si-B-C-N ceramic has been carried out in its raw materials, preparation process, microstructure, structural stability, oxidation resistance, creep resistance, fiber preparation, as well as film preparation and its relevant properties. The above mentioned three preparation methods have their own advantages, and the products may be widely applied, especially in the fields at high temperatures. However, disadvantages also exist in these methods, and theoretical research or application development of the Si-B-C-N ceramic is still confronted with many difficulties. In the future, further study is required on basic research, such as structural features, potential properties, oxidation mechanism or crystallization kinetics. At the same time, more efforts need to be made on the application research of this ceramic, including developing cheap or pollution-free raw 
materials, increasing ceramic yield, exploring advanced operation process, optimizing processing parameters, and preparing dense bulk ceramics especially with large dimensions or ceramic products for various applications.

\section{Acknowledgement}

The authors are grateful to the financial supports from the National Natural Science Foundation of China (Nos. 51072041, 50902031 and 51021002) and the National Science Foundation for Distinguished Young Scholars of China (No. 51225203).

\section{References}

[1] Baldus HP, Wagner O, Jansen M. Synthesis of advanced ceramics in the systems $\mathrm{Si}-\mathrm{B}-\mathrm{N}$ and Si-B-N-C employing novel precursor compounds. Mater Res Symp Proc 1992, 271: 821-826.

[2] Wideman T, Su K, Remsen EE, et al. Synthesis, characterization, and ceramic conversion reactions of borazine/silazane copolymers - new polymeric precursors to sincb ceramics. Chem Mater 1995, 7: 2203-2212.

[3] Bill J, Kamphowe TW, Muller A, et al. Precursor-derived Si-(B-)C-N ceramics: Thermolysis, amorphous state and crystallization. Appl Organomet Chem 2001, 15: 777-793.

[4] Su K, Remsen EE, Zank GA, et al. Synthesis, characterization, and ceramic conversion reactions of borazine-modified hydridopolysilazanes - new polymeric precursors to sincb ceramic composites. Chem Mater 1993, 5: 547-556.

[5] Weinmann M, Haug R, Bill J, et al. Boron-containing polysilylcarbodi-imides: A new class of molecular precursors for Si-B-C-N ceramics. J Organomet Chem 1997, 541: 345-353.

[6] Gao Y, Mera G, Nguyen H, et al. Processing route dramatically influencing the nanostructure of carbon-rich $\mathrm{SiCN}$ and $\mathrm{SiBCN}$ polymer-derived ceramics. Part I: Low temperature thermal transformation. $J$ Eur Ceram Soc 2012, 32: 1857-1866.

[7] Muller A, Gerstel P, Weinmann M, et al. Correlation of boron content and high temperature stability in Si-B-C-N ceramics. J Eur Ceram Soc 2000, 20: 2655-2659.

[8] Weinmann M, Kamphowe TW, Schuhmacher J, et al. Design of polymeric Si-B-C-N ceramic precursors for application in fiber-reinforced composite materials. Chem Mater 2000, 12: 2112-2122.

[9] Riedel R, Ruswisch LM, An LN, et al. Amorphous silicoboron carbonitride ceramic with very high viscosity at temperatures above $1500{ }^{\circ} \mathrm{C} . \mathrm{J} \mathrm{Am}$ Ceram Soc 1998, 81: 3341-3344.

[10] Weinmann M, Schuhmacher J, Kummer H, et al. Synthesis and thermal behavior of novel Si-B-C-N ceramic precursors. Chem Mater 2000, 12: 623-632.

[11] Bunjes N, Muller A, Sigle W, et al. Crystallization of polymer-derived $\mathrm{SiC} / \mathrm{BN} / \mathrm{C}$ composites investigated by TEM. J Non-Cryst Solids 2007, 353: 1567-1576.

[12] Kumar R, Cai Y, Gerstel P, et al. Processing, crystallization and characterization of polymer derived nano-crystalline Si-B-C-N ceramics. J Mater Sci 2006, 41: 7088-7095.

[13] Kumar R, Phillipp F, Aldinger F. Oxidation induced effects on the creep properties of nano-crystalline porous Si-B-C-N ceramics. Mat Sci Eng A-Struct 2007, 445-446: 251-258.

[14] Seyferth D, Plenio H. Borasilazane polymeric precursors for borosilicon nitride. J Am Ceram Soc 1990, 73: 2131-2133.

[15] Riedel R, Kienzle A, Dressler W, et al. A silicoboron carbonitride ceramic stable to $2,000^{\circ} \mathrm{C}$. Nature 1996 , 382: 796-798.

[16] Riedel R, Bill J, Kienzle A. Boron-modified inorganic polymers-precursors for the synthesis of multicomponent ceramics. Appl Organomet Chem 1996, 10: 241-256.

[17] Jansen M, Jaschke B, Jaschke TJ. Amorphous mulitnary ceramics in the Si-B-N-C system. Struct Bond 2002, 101: 137-191.

[18] Yan X-B, Gottardo L, Bernard S, et al. Ordered mesoporous silicoboron carbonitride materials via preceramic polymer nanocasting. Chem Mater 2008, 20: 6325-6334.

[19] Lee SH, Weinmann M, Aldinger F. Processing and properties of $\mathrm{C} / \mathrm{Si}-\mathrm{B}-\mathrm{C}-\mathrm{N}$ fiber-reinforced ceramic matrix composites prepared by precursor impregnation and pyrolysis. Acta Mater 2008, 56: 1529-1538.

[20] Colombo P, Mera G, Riedel R, et al. Polymer-derived ceramics: 40 years of research and innovation in advanced ceramics. J Am Ceram Soc 2010, 93: 1805-1837.

[21] Vlcek J, Potocky T, Cizek J, et al. Reactive magnetron sputtering of hard Si-B-C-N films with a high-temperature oxidation resistance. $J$ Vac Sci Technol A 2005, 23: 1513-1522.

[22] Čapek J, Hřeben S, Zeman P, et al. Effect of the gas mixture composition on high-temperature behavior of magnetron sputtered Si-B-C-N coatings. Surf Coat 
Tech 2008, 203: 466-469.

[23] Houska J, Vlcek J, Potocky S, et al. Influence of substrate bias voltage on structure and properties of hard Si-B-C-N films prepared by reactive magnetron sputtering. Diam Relat Mater 2007, 16: 29-36.

[24] Vijayakumar A, Warren A, Todi R, et al. Photoluminescence from RF sputtered SiCBN thin films. J Mater Sci: Mater in Elect 2009, 20: 144-148.

[25] Yang ZH, Jia DC, Zhou Y, et al. Fabrication and characterization of amorphous SiBCN powders. Ceram Int 2007, 33: 1573-1577.

[26] Zhang P, Jia D, Yang Z, et al. Microstructural features and properties of nano-crystalline $\mathrm{SiC} / \mathrm{BN}(\mathrm{C})$ composite ceramic prepared from mechanically alloyed SiBCN powder. J Alloy Compd 2012, 537: 346-356.

[27] Yang ZH, Zhou Y, Jia DC, et al. Microstructures and properties of $\mathrm{SiB}_{0.5} \mathrm{C}_{1.5} \mathrm{~N}_{0.5}$ ceramics consolidated by mechanical alloying and hot pressing. Mat Sci Eng A-Struct 2008, 489: 187-192.

[28] Lee SH, Weinmann $\mathrm{M}$, Gerstel $\mathrm{P}$, et al. Extraordinary thermal stability of $\mathrm{SiC}$ particulate-reinforced polymer-derived Si-B-C-N composites. Scripta Mater 2008, 59: 607-610.

[29] Tavakoli AH, Gerstel P, Golczewski JA, et al. Kinetic effect of boron on the crystallization of $\mathrm{Si}_{3} \mathrm{~N}_{4}$ in Si-B-C-N polymer-derived ceramics. $J$ Mater Res 2011, 26: 600-608.

[30] Muller A, Peng JQ, Seifert HJ, et al. Si-B-C-N ceramic precursors derived from dichlorodivinylsilane and chlorotrivinylsilane. 2 . Ceramization of polymers and high-temperature behavior of ceramic materials. Chem Mater 2002, 14: 3406-3412.

[31] Wang Z-C, Aldinger F, Riedel R. Novel Silicon-Boron-Carbon-Nitrogen materials thermally stable up to $2200^{\circ} \mathrm{C}$. $\mathrm{J} \mathrm{Am}$ Ceram Soc 2001, 84: 2179-2183.

[32] Jeschke G, Kroschel M, Jansen M. A magnetic resonance study on the structure of amorphous networks in the Si-B-N(-C) system. J Non-Cryst Solids 1999, 260: 216-227.

[33] Sneddon LG, Brunner AR, Su K, et al. Synthesis, characterization, and ceramic conversion reactions of pinacolborane-modified polyvinylsiloxane: A new polymeric precursor to boron-modified SiC. Abstr Pap Am Chem S 1999, 218: U846-U846.

[34] Nghiem QD, Kim DP. Polymerization of borazine with tetramethyldivinyldisilazane as a new class SiCBN preceramic polymer. J Ind Eng Chem 2006, 12: $905-910$.

[35] Haberecht J, Nesper R, Grutzmacher H. A construction kit for Si-B-C-N ceramic materials based on borazine precursors. Chem Mater 2005, 17 : 2340-2347.

[36] Cizek J, Vlcek J, Potocky S, et al. Mechanical and optical properties of quaternary Si-B-C-N films prepared by reactive magnetron sputtering. Thin Solid Films 2008, 516: 7286-7293.

[37] Zhang P, Jia D, Yang Z, et al. Crystallization and microstructural evolution process from the mechanically alloyed amorphous $\mathrm{SiBCN}$ powder to the hot-pressed nano $\mathrm{SiC} / \mathrm{BN}(\mathrm{C})$ ceramic. J Mater Sci 2012, 47: 7291-7304.

[38] Jia D, Zhang P, Yang Z, et al. Progress of amorphous and nanostructured $\mathrm{Si}-\mathrm{B}(\mathrm{Al})-\mathrm{C}-\mathrm{N}$ ceramics. Materials China 2011, 30: 5-11 (in Chinese).

[39] Riedel R, Mera G, Hauser R, et al. Silicon-based polymer-derived ceramics: Synthesis properties and applications - A review. J Ceram Soc Jpn 2006, 114: 425-444.

[40] Wilden J, Wank A. TPCVD synthesis of Si(-B)-C-N coatings. In ISPC 15. 2001.

[41] Vishnyakov VM, Ehiasarian AP, Vishnyakov VV, et al. Amorphous Boron containing silicon carbo-nitrides created by ion sputtering. Surf Coat Tech 2011, 206: 149-154.

[42] Zhang P, Jia D, Yang Z, et al. Physical and surface characteristics of mechanically alloyed SiBCN powder. Ceram Int 2012, 38: 6399-6404.

[43] Yu Z, Zhou C, Li R, et al. Synthesis and ceramic conversion of a novel processible polyboronsilazane precursor to SiBCN ceramic. Ceram Int 2012, 38: 4635-4643.

[44] Lee JS, Butt DP, Baney RH, et al. Synthesis and pyrolysis of novel polysilazane to $\mathrm{SiBCN}$ ceramic. $J$ Non-Cryst Solids 2005, 351: 2995-3005.

[45] Aldinger F, Weinmann M, Bill J. Precursor-derived Si-B-C-N ceramics. Anglais 1998, 70: 439-448.

[46] Bill J, Aldinger F. Precursor-derived covalent ceramics. Adv Mater 1995, 7: 775-787.

[47] Tavakoli AH, Gerstel P, Golczewski JA, et al. Quantitative X-ray diffraction analysis and modeling of the crystallization process in amorphous Si-B-C-N polymer-derived ceramics. J Am Ceram Soc 2010, 93: 1470-1478.

[48] Zern A, Mayer J, Janakiraman N, et al. Quantitative EFTEM study of precursor-derived Si-B-C-N ceramics. J Eur Ceram Soc 2002, 22: 1621-1629.

[49] Tavakoli AH, Gerstel P, Golczewski JA, et al. Effect of boron on the crystallization of amorphous Si-(B-)C-N polymer-derived ceramics. J Non-Cryst Solids 2009, 355: 2381-2389.

[50] Wideman T, Fazen $\mathrm{PJ}, \mathrm{Su} \mathrm{K}$, et al. 
Second-generation polymeric precursors for $\mathrm{BN}$ and SiNCB ceramic materials. Appl Organomet Chem 1998, 12: 681-693.

[51] Kern F, Gadow R. Liquid phase coating process for protective ceramic layers on carbon fibers. Surf Coat Tech 2002, 151-152: 418-423.

[52] Bharadwaj L, Fan Y, Zhang LG, et al. Oxidation behavior of a fully dense polymer-derived amorphous silicon carbonitride ceramic. J Am Ceram Soc 2004, 87: 483-486.

[53] Houska J, Warschkow O, Bilek MMM, et al. The effect of argon on the structure of amorphous SiBCN materials: an experimental and ab initio study. $J$ Phys-Condens Mat 2006, 18: 2337-2348.

[54] Vijayakumar A, Todi RM, Sundaram KB. Effect of $\mathrm{N}_{2} /$ Ar gas mixture composition on the chemistry of SiCBN thin films prepared by RF reactive sputtering. J Electrochem Soc 2007, 154: H271-H274.

[55] Zhang P, Jia D, Yang Z, et al. Influence of ball milling parameters on the structure of the mechanically alloyed SiBCN powder. Ceram Int 2012, 47: 7291-7304.

[56] Zeman P, Čapek J, Čerstvý R, et al. Thermal stability of magnetron sputtered Si-B-C-N materials at temperatures up to $1700^{\circ} \mathrm{C}$. Thin Solid Films 2010, 519: 306-311.

[57] Müller A, Zern A, Gerstel P, et al. Boron-modified poly(propenylsilazane)-derived Si-B-C-N ceramics: preparation and high temperature properties. J Eur Ceram Soc 2002, 22: 1631-1643.

[58] Gerstel P, Muller A, Bill J, et al. Synthesis and high-temperature behavior of $\mathrm{Si} / \mathrm{B} / \mathrm{C} / \mathrm{N}$ precursor-derived ceramics without "free carbon". Chem Mater 2003, 15: 4980-4986.

[59] Christ M, Zimmermann A, Zern A, et al. High temperature deformation behavior of crystallized precursor-derived Si-B-C-N ceramics. J Mater Sci 2001, 36: 5767-5772.

[60] Yang ZH, Jia DC, Zhou Y, et al. Processing and characterization of $\mathrm{SiB}_{0.5} \mathrm{C}_{1.5} \mathrm{~N}_{0.5}$ produced by mechanical alloying and subsequent spark plasma sintering. Mat Sci Eng A-Struct 2008, 488: 241-246.

[61] Christ M, Thurn G, Weinmann $\mathrm{M}$, et al. High-temperature mechanical properties of Si-B-C-N-precursor-derived amorphous ceramics and the applicability of deformation models developed for metallic glasses. J Am Ceram Soc 2000, 83: 3025-3032.

[62] Kumar NVR, Mager R, Cai Y, et al. High temperature deformation behaviour of crystallized
Si-B-C-N ceramics obtained from a boron modified poly(vinyl)silazane polymeric precursor. Scripta Mater 2004, 51: 65-69.

[63] Jansen M. Highly stable ceramics through single source precursors. Solid State Ion 1997, 101: 1-7.

[64] Jansen M, Jongermann H. A new class of promising ceramics based on amorphous inorganic networks. Curr Opin Solid St M 1997, 2: 150-157.

[65] Baldus P, Jansen M, Sporn D. Ceramic fibers for matrix composites in high-temperature engine applications. Science 1999, 285: 699-703.

[66] Yang ZH, Jia DC, Duan XM, et al. Microstructure and thermal stabilities in various atmospheres of $\mathrm{SiB}_{0.5} \mathrm{C}_{1.5} \mathrm{~N}_{0.5}$ nano-sized powders fabricated by mechanical alloying technique. J Non-Cryst Solids 2010, 356: 326-333.

[67] Ye D, Jia DC, Yang Z, et al. Microstructures and mechanical properties of SiBCNAl ceramics produced by mechanical alloying and subsequent hot pressing. J Zhejiang Univ-Sci A 2010, 11: 761-765.

[68] Butchereit E, Nickel KG, Muller A. Precursor-derived Si-B-C-N ceramics: Oxidation kinetics. J Am Ceram Soc 2001, 84: 2184-2188.

[69] Cinibulk MK, Parthasarathy TA. Characterization of oxidized polymer-derived SiBCN fibers. $J \mathrm{Am}$ Ceram Soc 2001, 84: 2197-2202.

[70] Vlcek J, Hreben S, Kalas J, et al. Magnetron sputtered Si-B-C-N films with high oxidation resistance and thermal stability in air at temperatures above $1500^{\circ} \mathrm{C}$. J Vac Sci Technol A 2008, 26: 1101-1108.

[71] Yang ZH. Microstructure and high-temperature properties of the Si-B-C-N MA-powders and ceramics. Ph.D. Thesis. Harbin (China): Harbin Institute of Technology, 2008.

[72] Hermann AM, Wang YT, Ramakrishnan PA, et al. Structure and electronic transport properties of Si-(B)-C-N ceramics. J Am Ceram Soc 2001, 84: 2260-2264.

[73] Petrman V, Houska J, Kos S, et al. Effect of nitrogen content on electronic structure and properties of SiBCN materials. Acta Mater 2011, 59: 2341-2349.

[74] Lee $\mathrm{SH}$, Weinmann M. $\mathrm{C}_{\text {fiber }} / \mathrm{SiC}_{\text {filler }} / \mathrm{Si}-\mathrm{B}-\mathrm{C}-\mathrm{N}_{\text {matrix }}$ composites with extremely high thermal stability. Acta Mater 2009, 57: 4374-4381.

[75] Nghiem QD, Jeon JK, Hong LY, et al. Polymer derived Si-C-B-N ceramics via hydroboration from borazine derivatives and trivinylcyclotrisilazane. $J$ Organomet Chem 2003, 688: 27-35. 